\title{
Structure and inhibition of the SARS-CoV-2 main protease reveals strategy for developing dual inhibitors against $M^{\text {pro }}$ and cathepsin $L$
}

\author{
Michael Dominic Sacco, ${ }^{1}$ Chunlong Ma, ${ }^{2}$ Panagiotis Lagarias, ${ }^{3}$ Ang Gao, ${ }^{2}$ Julia Alma Townsend, ${ }^{4}$ Xiangzhi \\ Meng, ${ }^{5}$ Peter Dube, ${ }^{5}$ Xiujun Zhang, ${ }^{1}$ Yanmei Hu, ${ }^{2}$ Naoya Kitamura, ${ }^{2}$ Brett Hurst, ${ }^{6,7}$ Bart Tarbet, ${ }^{6,7}$ Michael \\ Thomas Marty, ${ }^{4}$ Antonios Kolocouris, ${ }^{3}$ Yan Xiang, ${ }^{5}$ Yu Chen,,${ }^{1,}$ Jun Wang ${ }^{2, *}$ \\ 1Department of Molecular Medicine, Morsani College of Medicine, University of South Florida, Tampa, FL, 33612, USA. ²Department of Pharmacology and Toxicology, \\ College of Pharmacy, The University of Arizona, Tucson, AZ, 85721, USA. ${ }^{3}$ Department of Pharmaceutical Chemistry, Faculty of Pharmacy, National and Kapodistrian \\ University of Athens, Athens, 15771, Greece. ${ }^{4}$ Department of Chemistry and Biochemistry, The University of Arizona, Tucson, AZ, 85721, USA. ${ }^{5}$ Department of Microbiology, \\ Immunology and Molecular Genetics, University of Texas Health Science Center at San Antonio, San Antonio, TX, 78229, USA. ${ }^{6}$ Institute for Antiviral Research, Utah State \\ University, Logan, UT, 84322, USA. ${ }^{7}$ Department of Animal, Dairy and Veterinary Sciences, Utah State University, Logan, UT, 84322, USA. \\ *Corresponding author. Email: junwang@pharmacy.arizona.edu (J. W.) and ychen1@usf.edu (Y. C.)
}

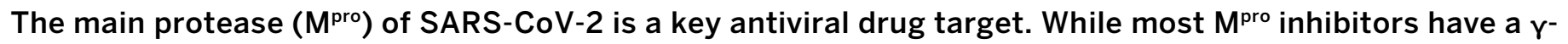
lactam glutamine surrogate at the $\mathrm{P} 1$ position, we recently discovered several $\mathrm{M}^{\text {pro }}$ inhibitors have hydrophobic moieties at the P1 site, including calpain inhibitors II and XII, which are also active against human cathepsin L, a host-protease that is important for viral entry. In this study, we solved X-ray crystal structures of $\mathrm{M}^{\text {pro }}$ in complex with calpain inhibitors II and XII, and three analogs of GC-376. The structure of $\mathrm{M}^{\text {pro }}$ with calpain inhibitor II confirmed the $\mathrm{S1}$ pocket can accommodate a hydrophobic methionine side chain, challenging the idea that a hydrophilic residue is necessary at this position. Interestingly, the structure of calpain inhibitor XII revealed an unexpected, inverted binding pose. Taken together, the biochemical, computational, structural, and cellular data presented herein provide new directions for the development of dual inhibitors as SARS-CoV-2 antivirals.

\section{INTRODUCTION}

The COVID-19 pandemic emerged in late December 2020 in Wuhan, China and evolved to be one of the worst public health crisis in modern history. The impact of COVID-19 on global public health and economy has been severe. The etiological agent of COVID-19 is SARS-CoV-2, which shares $\sim 78 \%$ genetic similarity with SARS-CoV, the virus that led to the SARS outbreak in 2003. Although coronavirus outbreaks such as COVID-19 are not unpredicted, the high mortality rate and the ease of transmission of SARS-CoV-2 is unprecedented.

Currently there are few antivirals and no vaccines available for SARS-CoV-2. As such, it is imperative to identify drug targets that could lead to effective antivirals. Guided by research of similar coronaviruses, SARS-CoV and MERS-CoV, several viral proteins have been prioritized as SARS-CoV-2 antiviral drug targets: the spike protein, the RNA-dependent RNA polymerase (RdRp), the main protease $\left(\mathrm{M}^{\mathrm{pro}}\right)$, and the papain-like protease $\left(\mathrm{PL}^{\mathrm{pro}}\right)(1,2)$. The SARS-CoV-2 RdRp inhibitor remdesivir was granted emergency use authorization from FDA on May $1^{\text {st }} 2020$. Remdesivir has broad-spectrum antiviral activity against SARS-CoV, SARS-CoV-2, and MERS$\mathrm{CoV}$ in cell culture (3-5). The antiviral efficacy was further confirmed in MERS-CoV infection mouse and rhesus macaque models $(6,7)$. Additional RdRp inhibitors under investigation for SARS-CoV-2 include EIDD-2801, favipiravir (T-705), ribavirin, and galidesivir $(8,9)$. The fusion inhibitor EK1C4, which was designed based on the $\mathrm{H} 2$ peptide in the $\mathrm{S} 2$ domain of the HCoV-OC43 spike protein, showed promising broad-spectrum antiviral activity against SARS-CoV-2, SARS-CoV, MERS-CoV, as well as human coronaviruses HCoV-229E, HCoV-NL63, and HCoV-OC43 (10, 11). Meanwhile, the $\mathrm{M}^{\text {pro }}$ has been extensively explored as a drug target for not only SARS-CoV-2, but also SARS-CoV, MERS-CoV, as well as enteroviruses, rhinoviruses, and noroviruses (12). $\mathrm{M}^{\text {pro }}$ is a viral encoded cysteine protease that has a unique substrate preference for a glutamine residue at the P1 site, which was recently confirmed by substrate profiling for SARS-CoV2 (13). Consequently, the majority of designed $\mathrm{M}^{\text {pro }}$ inhibitors contain either 2-pyrrolidone or 2-piperidinone at the P1 site as a mimetic of the glutamine residue in the substrate (14). Examples include compounds N3, 13b, 11a, 11b, and our recently identified GC-376 (15-18). all of which have potent enzymatic inhibition in biochemical assay and antiviral activity in cell culture. Their mechanism of action and mode of inhibition were revealed by the drug-bound X-ray crystal structures (15-18).

Interestingly, our previous study discovered two un- 
conventional SARS-CoV-2 $\mathrm{M}^{\text {pro }}$ inhibitors, calpain inhibitors II and XII, that are structurally dissimilar to the traditional $\mathrm{M}^{\text {pro }}$ inhibitors, such as GC-376 (15). Specifically, calpain inhibitors II and XII incorporate the hydrophobic methionine and norvaline side chains in the P1 position respectively. This discovery challenges the idea that a hydrophilic glutamine mimetic is required at the P1 position. Furthermore, calpain inhibitor II is a potent inhibitor of human protease cathepsin $\mathrm{L}$, with a $\mathrm{K}_{\mathrm{i}}$ of $50 \mathrm{nM}$ (19). Cathepsin L plays an important role in SARS-CoV-2 viral entry by activating the viral spike protein in the endosome or lysosome (20-22), and has a relatively broad substrate preference at the P1 position $(23,24)$. Studies have indicated that cathepsin L inhibitors such as MDL28170 can block or significantly decrease virus entry (20, $25)$. In this study, we are exploring two series of $M^{\text {pro }}$ inhibitors, one is the dual inhibitors targeting both $\mathrm{M}^{\text {pro }}$ and cathepsin L such as calpain inhibitors II and XII, and another is the $\mathrm{M}^{\text {pro }}$-specific inhibitors such as GC-376 analogs UAWJ246, 247, and 248. To dissect the mechanism of action of dual inhibitors, we solved the high-resolution X-ray crystal structures of $\mathrm{M}^{\text {pro }}$ with calpain inhibitors II and XII. We found that calpain inhibitor II is bound to $\mathrm{M}^{\text {pro }}$ in the canonical, extended conformation, but calpain inhibitor XII adopts an unexpected binding mode, where it assumes an inverted, semi-helical conformation in which the P1' pyridine ring is placed in the S1 pocket instead of the P1 norvaline sidechain, as one would expect. The complex structures of calpain inhibitors II and XII, together with the structure-activity relationship studies, reveal the S1 pocket of $\mathrm{M}^{\text {pro }}$ can accommodate both hydrophilic and hydrophobic substitutions, paving the way for the design of dual inhibitors that target both the viral $\mathrm{M}^{\text {pro }}$ and host cathepsin L. Finally, guided by the X-ray crystal structure of SARS-CoV-2 $\mathrm{M}^{\text {pro }}$ with GC-376

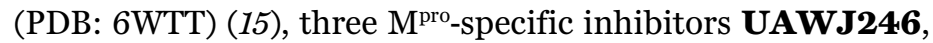
UAWJ247, and UAWJ248 were designed to profile the sidechain preferences of the S1', S2, S3 and S4 pockets. Overall, the X-ray crystal structures and activity profile presented herein offer valuable insights into the substrate promiscuity of $\mathrm{M}^{\text {pro }}$, as well as a new direction in the designing of dual inhibitors targeting both the SARS-CoV-2 $\mathrm{M}^{\text {pro }}$ and host cathepsin L.

\section{RESULTS AND DISCUSSION \\ SARS-CoV-2 Mro constructs used in this study}

Three $\mathrm{M}^{\text {pro }}$ constructs were used in this study: the tag-free native $\mathrm{M}^{\text {pro }}\left(\mathrm{M}^{\text {pro }}\right), \mathrm{M}^{\text {pro }}$ with two extra residues: histidine and methionine at the $\mathrm{N}$ terminus $\left(\mathrm{HM}-\mathrm{M}^{\text {pro }}\right)$, the $\mathrm{M}^{\text {pro }}$ with a native $\mathrm{N}$ terminus, and a C-terminal his-tag ( $\left.\mathrm{M}^{\text {pro }}-\mathrm{His}\right)$. The tagfree $\mathrm{M}^{\text {pro }}$ was used for all functional assays, while the other two constructs were used for structure determination due to ease of crystallization. The HM-M ${ }^{\text {pro }}$ construct was used for the complex structures of all five compounds including calpain inhibitors II and XII, UAWJ246, UAWJ247, and UAWJ248 (fig. S1). In addition, the $\mathrm{M}^{\text {pro-His construct was }}$ also co-crystallized with UAWJ246 as a control for the potential influence of extra $\mathrm{HM}$ residues at the $\mathrm{N}$ terminus on the $\mathrm{M}^{\text {pro }}$ structure and drug binding.

The $\mathrm{M}^{\text {pro }}$-His and the native $\mathrm{M}^{\text {pro }}$ have similar enzymatic activity with $k_{\text {cat }} / \mathrm{K}_{\mathrm{m}}$ values of $6,689 \mathrm{~s}^{-1} \mathrm{M}^{-1}, 5,748 \mathrm{~s}^{-1} \mathrm{M}^{-1}$, respectively (fig. S2A). The HM-M ${ }^{\text {pro }}$ construct has significantly reduced enzymatic activity with a $k_{\text {cat }} / \mathrm{K}_{\mathrm{m}}$ value of $214 \mathrm{~s}^{-1} \mathrm{M}^{-1}$, which is about $3.7 \%$ of the $\mathrm{M}^{\text {pro }}\left(k_{\text {cat }} / \mathrm{K}_{\mathrm{m}}=5,748 \mathrm{~s}^{-1} \mathrm{M}^{-1}\right)$ (fig. $\mathrm{S} 2 \mathrm{~A})$. This was expected as it has been shown that $\mathrm{M}^{\text {pro }}$ requires dimerization to be catalytically active and the N-terminal finger plays an essential role in dimerization (26). Specifically, the first residue serine (Ser1) from one protomer interacts with the Glu166 of the adjacent protomer, a feature that is important for catalytic activity (fig. S2B). Nevertheless, the HM-M ${ }^{\text {pro }}$ turned out to be an excellent construct for crystallization, and we were able to determine several high-resolution drug-bound X-ray crystal structures. In contrast, efforts to obtain high-quality crystals with the $\mathrm{M}^{\text {pro-His con- }}$ struct was challenging, because of the localization of the disordered His-tag at the crystal packing interface (15). Several previous studies similarly used the enzymatically inactive $\mathrm{M}^{\text {pro }}$ with extra residues at the $\mathrm{N}$ terminus for the structural studies, and the ligand binding poses were identical to those with tag-free $\mathrm{M}^{\text {pro }}$ (e.g., PDB 7BRP vs $6 \mathrm{WNP}, 6 \mathrm{WTJ}$ vs $6 \mathrm{~L} 70$ ) (27-30). Therefore, the use of enzymatic inactive HM-M ${ }^{\text {pro }}$ construct for crystallographic study of inhibitor binding is justified.

\section{$X$-ray crystal structures of SARS-CoV-2 $M^{\text {pro }}$ in complex with calpain inhibitors II and XII}

Previous studies have shown SARS-CoV and SARS-CoV-2 M Mro $^{\text {ro }}$ cleave polyproteins at P2-P1 $\downarrow$ P1' where P1' is a residue with a small side chain (Ala, Ser, or Gly), P1 is glutamine and P2 is a large, hydrophobic residue, such as leucine or phenylalanine $(13,31,32)$. This consensus sequence has operated as the foundation for extensive inhibitor designs where a reactive warhead, usually an aldehyde, $\alpha, \beta$-unsaturated ester, or $\alpha$-ketoamide, is linked to a glutamine surrogate pyrrolidone that is connected to a hydrophobic residue via an amide bond (12, 33-35). This strategy has been largely successful, with the development of inhibitors such as GC-376 and 13b that have $\mathrm{IC}_{50}$ values in the low $\mathrm{nM}$ range for SARS-CoV-2 $\mathrm{M}^{\text {pro }}(15,17)$.

We recently reported calpain inhibitors II and XII and boceprevir have low $\mu \mathrm{M} \mathrm{IC}_{50}$ values against SARS-CoV-2 $\mathrm{M}^{\text {pro }}$ (15). Importantly, these compounds have a hydrophobic side chain at the P1 position, challenging the notion that a hydrophilic moiety is required at this position. This has previously been demonstrated with SARS-CoV $\mathrm{M}^{\text {pro }}$, where the aldehyde inhibitor Cm-FF-H binds with a $\mathrm{K}_{\mathrm{i}}$ of $2.24 \pm 0.58 \mu \mathrm{M}$ despite having a phenylalanine at the $\mathrm{P} 1$ position (36). The observed 
substrate plasticity is in part attributed to the reactivity of the electrophilic warhead aldehyde with the catalytic cysteine, which offsets the requirement for favorable interactions with the hydrophilic S1 subsite. Furthermore, it introduces the prospect of modifying the P1 residue so that it interacts with multiple host or viral proteases that are essential for promoting SARS-CoV-2 viral entry or replication, which would increase antiviral spectrum and genetic barrier to drug resistance. To visualize the interactions between the P1 site and the hydrophobic S1 pocket, we solved the complex structures of SARS-CoV-2 $\mathrm{M}^{\text {pro }}$ with calpain inhibitor II and calpain inhibitor XII.

The crystal structures of the SARS-CoV-2 HM-M ${ }^{\text {pro }}$ in complex with calpain inhibitors II (PDB: 6XA4) and XII (PDB: $6 \mathrm{XFN}$ ) were solved in the $\mathrm{C} 2$ space group at 1.65 and $1.70 \AA$ resolution with an $\mathrm{R}_{\text {work }} / \mathrm{Rf}_{\text {ree }}$ of $0.206 / 0.245$ and $0.205 / 0.232$ respectively, with one protomer per asymmetric unit (Fig. 1 and Table S1). Like other peptidomimetic aldehyde inhibitors, the thiohemiacetal of calpain inhibitor II occupies the oxyanion hole formed by the backbone amide groups of Gly143, Ser144, and Cys145 (Fig. 1A). Here it adopts the (S) configuration, which is typical for most $\mathrm{M}^{\text {pro }}$ aldehyde inhibitors, although the $(\mathrm{R})$ configuration has also been observed $(15,37)$. Like previous $\mathrm{M}^{\text {pro }}$ and cathepsin L complex structures, the body of the inhibitor extends the length of the substrate-binding channel, with the side chains placed in their respective recognition pockets. The $\mathrm{P} 1$ methionine side chain projects into the S1 subsite where the sulfur forms a weak hydrogen bond with His163. The P2 leucine side chain forms hydrophobic interactions in the $\mathrm{S} 2$ pocket, while the P3 leucine occupies the solvent-accessible S3 position. Multiple hydrogen bonds form between the inhibitor amide backbone and the main chains of His164, Met165, and Glu166.

In contrast to the pose of calpain inhibitor II, calpain inhibitor XII demonstrates an atypical binding mode where it adopts an inverted, semi-helical conformation that wraps around the catalytic core (PDB: 6XFN) (Fig. 1B). This is dissimilar to the extended configuration of previously published peptidomimetic inhibitors, including other $\alpha$-ketoamide compounds such as 13b (Fig. 1, C and D) (18). For calpain inhibitor XII, the P1' pyridine is placed in the S1 site while the P1 norvaline occupies the S1' site. The P2 leucine projects outwards toward the solvent near the TSEDMLN loop (residues 45-51) and the terminal carboxybenzyl (Cbz) group curls back toward the S1 site, forcing Asn142 upwards while forming a water-mediated hydrogen bond with Glu166. Corresponding to this unique binding pose, we observed the $(\mathrm{R})$ configuration of the thiohemiketal-Cys145 adduct for the first time among the known $\alpha$-ketoamide inhibitors (Fig. 1D). From our recent X-ray crystal structure of the SARS-CoV-2 $\mathrm{M}^{\text {pro }}$ in complex with GC-376 (PDB: 6WTT) (15), it is known that the thiohemiacetal center of aldehyde-based inhibitors can assume either an (R) or (S) configuration, depending on which face of the aldehyde group undergoes nucleophilic attack from the thiolate of Cys145 during covalent bond formation (15). In contrast, the thiohemiketal group of all crystallographic solved $\alpha$-ketoamide $\mathrm{M}^{\text {pro }}$ inhibitors such as $\mathbf{N 3}$ and 13b adopts the (S) configuration (Fig. 1, C and D) (16, 17). The new calpain inhibitor XII structure demonstrates that, like aldehyde-based inhibitors, the covalent adduct formed between $\alpha$-ketoamide compounds and the catalytic cysteine can assume two different configurations as well.

In both the (R) and (S) configurations of the thiohemiketal adducts, the hydroxyl group is placed near His41, while the amide oxygen is positioned in the oxyanion hole. However, the exact locations of these two functional groups result in different hydrogen bond patterns. Compared to other $\alpha$-ketoamide inhibitors, the unique binding mode of calpain inhibitor XII alters the hydrogen-bonding network of the catalytic core. The hydroxyl group forms a short hydrogen bond ( $2.5 \AA$ in length) with the catalytic His41, and two weak hydrogen bonds $(3.3 \AA)$ with the main chain carbonyl of His164 and a water molecule in the central channel between the S1 and S2 pockets (Fig. 1B). The ketoamide amide oxygen establishes three hydrogen bonds in the oxyanion hole (2.9, 3.2 and $3.1 \AA$ to the backbone $-\mathrm{NH}$ of Gly143, Ser144 and Cys145 respectively), and its nitrogen forms a hydrogen bond (3.1 $\AA$ ) with the mainchain carbonyl of His164 (Fig. 1B). In the canonical binding conformation for $\alpha$-ketoamide inhibitors, such as $\mathbf{1 3 b}$ and those described herein, the hydroxyl group establishes one standard hydrogen bond (2.8 $\AA$ ) with His41 and another hydrogen bond ( $3.3 \AA$ ) with a bulk water molecule (Fig. 1C). Meanwhile, the hydrogen bonds between the amide oxygen and the oxyanion hole now have distances of 3.3, 3.0 and $2.5 \AA$ respectively, while the amide nitrogen forms no hydrogen bond with the protein (Fig. 1C).

The S1 pocket recognizes the most conserved residue in the $\mathrm{M}^{\text {pro }}$ substrate, the P1 glutamine. Underscoring its importance for ligand binding, most specific $\mathrm{M}^{\text {pro }}$ inhibitors have a glutamine surrogate such as the pyrrolidone ring that occupies the S1 pocket. X-ray crystal structures of SARS-CoV$2 \mathrm{M}^{\text {pro }}$ in complex with compounds like calpain inhibitor II, calpain inhibitor XII, and boceprevir (PDB: 6WNP and 7BRP) prove that a hydrophobic side chain can also be accommodated in the $\mathrm{S} 1$ pocket. Like previous inhibitors, hydrophobic interactions are observed between the newly identified inhibitors and the backbone atoms of Leu141/Asn142/Met165. However, these interactions are further enhanced in calpain inhibitor XII, where its aromatic pyridine ring is stacked and sandwiched between the two planar peptide bonds involving Asn142 and Met165 (Fig. 1B). Furthermore, a hydrogen bond is observed between His163 and the methionine sulfur and pyridine nitrogen for calpain inhibitors II and XII, respectively (Fig. 1, A and B). 
To confirm the binding modes revealed by the X-ray crystal structures of calpain inhibitors II and XII, we designed two analogs, calpain inhibitor I and UAWJ257 (Fig. 2A). Specifically, to dissect the importance of the hydrogen bond between His163 and the sulfur atom from the methionine side chain of calpain inhibitor II, we designed the butyl analog, calpain inhibitor I (Fig. 2A). It was found that calpain inhibitor I has an $\mathrm{IC}_{50}$ that is $~ 10$-fold weaker than calpain inhibitor II (Fig. 2, B vs C). Similarly, this hydrogen bond is important for calpain inhibitor XII binding, since the benzene counterpart of calpain inhibitor XII, compound UAWJ257, has a significantly reduced activity against SARS-CoV-2 $\mathrm{M}^{\text {pro }}\left(\mathrm{IC}_{50}=64.5 \pm 15.4 \mu \mathrm{M}\right)$ (Fig. 2 , D vs E). Likewise, no binding was detected in the thermal shift assay $\left(\triangle \mathrm{T}_{\mathrm{m}}\right.$ $=-0.07^{\circ} \mathrm{C}$ ) for $\mathbf{U A W J 2 5 7}$, while calpain inhibitor I showed reduced binding compared to calpain inhibitor II (Fig. 2F). In addition to abolishing the hydrogen bond, the dramatic loss of inhibition of UAWJ257 might be attributed to a clash between the proton on His163N $\varepsilon 2$ and the benzene hydrogen that replaces the lone pair on the pyridine nitrogen, which lies only $3.1 \AA$ away from His163 $\mathrm{N} \varepsilon 2$. Overall, the structureactivity relationship results of calpain inhibitors II and XII are consistent with the binding poses shown in the X-ray crystal structures (Fig. 1).

While calpain inhibitor II was previously reported to inhibit cathepsin $\mathrm{L}$ with an inhibition constant $\mathrm{K}_{\mathrm{i}}$ of $0.6 \mathrm{nM}$ (19), which was confirmed by our data as well $\left(\mathrm{IC}_{50}=0.41 \mathrm{nM}\right)$ (Fig. 2G), the inhibition of cathepsin $\mathrm{L}$ by calpain inhibitor XII was unknown. We determined that calpain inhibitor XII is also a potent inhibitor of cathepsin $\mathrm{L}$, with an $\mathrm{IC}_{50}$ value of $1.62 \pm 0.33 \mathrm{nM}$ (Fig. 2H). Because cathepsin $\mathrm{L}$ has been shown to activate the SARS-CoV-2 spike protein, cathepsin L inhibitors are known to block viral entry (20). Importantly, this may provide an explanation for the superior antiviral activity of calpain inhibitor II and XII despite having inferior affinity for $\mathrm{M}^{\text {pro }}$ compared to the specific inhibitors GC-376, N3, UAWJ246, UAWJ247, and UAWJ248 $(15,18)$. Both calpain inhibitors II and XII had no detectable inhibition against the SARS-CoV-2 papain-like protease $\left(\mathrm{PL}^{\text {pro }}\right)\left(\mathrm{IC}_{50}>\right.$ $20 \mu \mathrm{M}$ ) (Fig. 2I), suggesting they are not non-specific cysteine protease inhibitors. Collectively, the X-ray crystal structures of SARS-CoV-2 HM-M ${ }^{\text {pro }}$ in complex with calpain inhibitors II and XII, along with the enzymatic assay results, suggest that it is feasible to develop dual inhibitors that simultaneously targeting the SARS-CoV-2 $\mathrm{M}^{\text {pro }}$ and the host cathepsin L, both of which are validated antiviral drug targets for SARS-CoV-2 $(20,21)$.

Rational design of $G C$-376 analogs and the $X$-ray crystal structures of SARS-CoV-2 $M^{\text {pro }}$ in complex with UAWJ246, UAWJ247, and UAWJ248

We recently demonstrated the inhibition of SARS-CoV-2 $\mathrm{M}^{\text {pro }}$ by GC-376, and solved the X-ray crystal structure of $\mathrm{M}^{\text {pro-His }}$ with GC-376 (PDB: 6WTT) (15). To profile the substrate spectrum of SARS-CoV-2 $\mathrm{M}^{\text {pro }}$ in the S1', S2, S3, and S4 sites, several GC-376 analogs were designed (Fig. 3A). Specifically, compound UAWJ246 was designed to occupy the S1' pocket according to the overlay structures of SARS-CoV-2 $\mathrm{M}^{\text {pro }}+\mathbf{G C}-$ 376 (PDB: 6WTT) and SARS-CoV $\mathrm{M}^{\text {pro }}(\mathrm{H} 41 \mathrm{~A})+$ substrate (PDB: 2Q6G) (fig. S3). UAWJ246 contains a pharmacological compliant $\alpha$-ketoamide reactive warhead with a cyclopropyl substitution. UAWJ247 was designed to probe the substrate promiscuity in the S2 pocket. In the X-ray crystal structure of $\mathrm{M}^{\text {pro-His }}$ with GC-376, the TSEDMLN loop (residues 45-51) constituting the S2 pocket exhibits significant flexibility among the three protomers in the asymmetric unit, indicating a variety of substitutions can be accommodated at this position. To test this hypothesis, UAWJ247 was designed with a benzyl substitution at the P2 position instead of the isopropyl in GC-376. UAWJ248 is a tripeptide and was designed to incorporate the P3 substitution. Enzyme kinetic studies showed that compounds UAWJ246 and UAWJ247 7 bound to $\mathrm{M}^{\text {pro }}$ reversibly with inhibition constant $\mathrm{K}_{\mathrm{I}}$ values of $0.036 \pm 0.007$ and $0.035 \pm 0.008 \mu \mathrm{M}$, respectively (Fig. 3, B and C). In contrast, the enzyme kinetic curves for compound UAWJ248 was similar to that of GC-376, which showed a biphasic progression character (fig. S4), suggesting UAWJ248 inhibits $\mathrm{M}^{\text {pro }}$ through a two-step process with an initial reversible binding followed by an irreversible inactivation. Fitting the progression curves with the two-step Morrison equation revealed the first step equilibrium dissociation constant $\mathrm{K}_{\mathrm{I}}$ and the second step reaction constant $k_{2}$ as 13.20 $\mathrm{nM}$ and $0.001195 \mathrm{~s}^{-1}$, respectively, which corresponds to an overall $k_{2} / \mathrm{K}_{\mathrm{I}}$ value of $9.05 \times 10^{4} \mathrm{M}^{-1} \mathrm{~s}^{-1}$ (Fig. 3D). In comparison, the $k_{2} / \mathrm{K}_{\mathrm{I}}$ value for GC-376 is $2.84 \times 10^{4} \mathrm{M}^{-1} \mathrm{~s}^{-1}$ (Fig. 3E), suggesting UAWJ248 is 3.2-fold more potent than GC-376. None of these compounds showed inhibition against the SARS-CoV-2 PL pro $\left(\mathrm{IC}_{50}>20 \mu \mathrm{M}\right)$ (Fig. 3F).

Next, we determined the mechanism of action with thermal shift binding assay and native mass spectrometry. As expected, binding of UAWJ246, UAWJ247, and UAWJ248 all stabilized SARS-CoV-2 $\mathrm{M}^{\text {pro }}$, as shown by the $\triangle \mathrm{T}_{\mathrm{m}}$ shift of $11.08,8.28$, and $18.10^{\circ} \mathrm{C}$, respectively (Fig. $3 \mathrm{G}$ ). All three com-

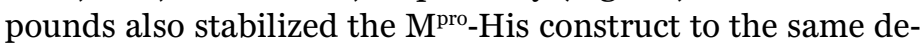
gree as the tag free $\mathrm{M}^{\text {pro }}$, suggesting these two constructs are functionally equivalent (Fig. 3G). In contrast, compounds UAWJ246 and UAWJ247 did not show stabilization for the HM-M ${ }^{\text {pro }}$ construct, while the more potent $\mathbf{G C - 3 7 6}$ and UAWJ248 stabilized this construct with $\Delta \mathrm{T}_{\mathrm{m}}$ shift of 2.45 , and $10.01^{\circ} \mathrm{C}$, respectively (Fig. $3 \mathrm{G}$ ).

The binding of all three compounds UAWJ246, 247, and $\mathbf{2 4 8}$ to $\mathrm{M}^{\text {pro }}$ was further confirmed by native mass spectrometry (Fig. 3, H-K). Like GC-376, addition of the ligands resulted in two new sets of peaks corresponding to one ligand 
per dimer and two ligands per dimer.

Most $\mathrm{M}^{\text {pro }}$ inhibitors with antiviral activity against SARSCoV-2 use an $\alpha$-ketoamide or aldehyde/bisulfite warhead to form a covalent adduct with the catalytic Cys145 $(15,17)$. We previously reported $\mathbf{G C - 3 7 6}$ as one of the most potent inhibitors of SARS-CoV-2 $\mathrm{M}^{\text {pro }}$ in vitro with an $\mathrm{IC}_{50}$ of $0.033 \mu \mathrm{M}$ and $\mathrm{EC}_{50}$ of $3.37 \mu \mathrm{M}$ in the enzymatic assay and antiviral CPE assay (15). Here we show the $\alpha$-ketoamide analog of GC-376, UAWJ246 has a comparable $\mathrm{IC}_{50}$ of $0.045 \mu \mathrm{M}$, suggesting the $\alpha$-ketoamide and the aldehyde are nearly equivalent in terms of inhibitory activity. We solved the complex structure of UAWJ246 with both SARS-CoV-2 HM-M $\mathrm{M}^{\text {pro }}$ at $1.45 \AA$ resolution with a $\mathrm{R}_{\text {work }} / \mathrm{R}_{\text {free }}$ of $0.189 / 0.213$ as a dimer (PDB:

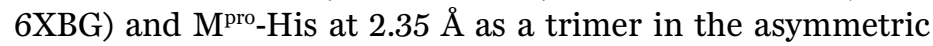
unit (Fig. 4, A and B; fig. S5). The binding pose of UAWJ246 in these two constructs was nearly superimposable (fig. S5), suggesting the use of enzymatic inactive HM-M $\mathrm{M}^{\text {pro }}$ construct for crystallographic study of inhibitor binding is justified. In the dimer structure of HM-M ${ }^{\text {pro }}$ with UAWJ246, the amide oxygen of the $\alpha$-ketoamide occupies the oxyanion hole, while the thiohemiketal hydroxide forms a hydrogen bond with the catalytic histidine, His41 (Fig. 4A). The cyclopropyl group extends partly into the S1' subpocket. Interestingly, the Cbz of UAWJ246 adopts a different conformation in each protomer (Fig. 4, A and B). In the A protomer of the $1.45 \AA$ resolution structure crystallized in $\mathrm{P} 2_{1}$ space group, the $\mathrm{Cbz}$ moiety extends the length of the S3 and S4 subsites, forcing residues 189-191 to flip outwards (Fig. 4A). In the B protomer, the $\mathrm{Cbz}$ moiety projects upwards, where the $\mathrm{S} 3$ sidechain is normally positioned (Fig. 4B). The A-conformation resembles that of GC-376 in our previously solved structure (PDB: 6WTT) (fig. S6A), whereas the B-conformation resembles GC-376 from PDB ID 7BRR (fig. S6B) (28). The downward conformation establishes extensive interactions with the $\mathrm{S} 4$ pocket, and may be one of the main reasons for the superior in vitro activity of GC-376 and its analogs. The upward conformation also forms favorable interactions with protein residues constituting the S3 site, including Glu166 and Gln189. Additionally, it enables the formation of intramolecular interactions between the benzyl ring and the P1 sidechain, similar to the hydrophobic intramolecular interactions formed between the P1 and P3 moieties in calpain inhibitor II and boceprevir, as well as, to some degree, the stacking between the pyridine and the Cbz linker of calpain inhibitor XII (Fig. 1B; fig. S7). It is likely that GC-376, UAWJ246, and other analogs exist in a dynamic equilibrium between these conformations and the captured crystallographic poses are, in part, determined by the crystal-packing interface between protomers and/or differences in the $\mathrm{pH}$ or ionic strength of the crystallization solution.

The chemical structure of UAWJ247 is nearly identical to $\mathbf{G C - 3 7 6}$, except for the replacement of its S2 isobutyl moiety for a benzyl group, analogous to a Leu $\rightarrow$ Phe exchange. To visualize the binding mode of UAWJ247, we solved the complex structure with SARS-CoV-2 $\mathrm{M}^{\text {pro }}$ at $1.60 \AA$ with an $\mathrm{R}_{\text {work }} / \mathrm{R}_{\text {free }}$ of $0.181 / 0.224$ in the $\mathrm{C} 2$ space group with one protomer per asymmetric unit (PDB: 6XBH) (Fig. 4, C and D). Like their chemical structures, the binding poses between UAWJ247 and GC-376 are very similar (Fig. 4D), with minor differences observed for Gln189 and the catalytic histidine, His41, which swivels toward the S2 benzyl group to form face-to-face $\pi$-stacking interactions. As expected, the $\mathrm{IC}_{50}$ of $0.045 \mu \mathrm{M}$ for UAWJ247 is very close to that of GC376 and consistent with the preference for a hydrophobic residue at the S2 site. This data also suggests replacing Leu for a larger Phe is tolerated, and that aromaticity can be incorporated into the $\mathrm{S} 2$ site for the purpose of improving pharmacokinetic properties or broadening the spectrum of activity, with limited effect on $\mathrm{M}^{\text {pro }}$ inhibition.

UAWJ248 was designed to occupy the additional S4 pocket compared to UAWJ246. We solved the complex structure of UAWJ248 with SARS-CoV-2 HM-M ${ }^{\text {pro }}$ at $1.70 \AA$ with an $\mathrm{R}_{\text {work }} / \mathrm{R}_{\text {free }}$ of $0.181 / 0.219$ as a dimer in the P1 monoclinic space group (PDB: 6XBI) (Fig. 4, E and F). The conformation is consistent in both protomers (fig. S8). The $\alpha$ ketoamide warhead forms an adduct with Cys145 in the (S) conformation, like other cyclopropane $\alpha$-ketoamide analogs described herein including UAWJ246 6 and previously published 13b (17). Similarly, the P1 $\gamma$-lactam and P2 isobutyl moieties occupy their respective S1 and S2 subsites. The P3 isobutyl orients upwards into the S3 site where it forms no meaningful interactions. However, the insertion of this additional leucine into the UAWJ246 core ensures the formation of a hydrogen bond with the main chain amide oxygen of Glu166. The terminal Cbz is placed in the S4-S5 site, where nonpolar interactions occur between the benzene and side chain of Pro168 and Ala191 and $\pi$ stacking with the main chain amides of Gln189, Thr190, and Ala191.

\section{Molecular dynamics simulations of SARS-COV-2 Mpro with inhibitors}

The binding interactions between the covalently bound calpain inhibitor II, calpain inhibitor XII, UAWJ246, UAWJ247, and UAWJ248, with SARS-CoV-2 $\mathrm{M}^{\text {pro }}$ were further explored using $100 \mathrm{~ns}-\mathrm{MD}$ simulations with starting structures the X-ray structures with PBD IDs 6XA4, 6XFN, 6XBG (dimer), 6XBH (monomer), 6XBI (dimer). The MD simulations verified the stability of the interactions inside the binding cavity of SARS-CoV-2 $\mathrm{M}^{\text {pro }}$ observed in the X-ray structures, as inspected from the trajectories and shown in frequency interaction plots (Fig. 5, A, C, E, G and fig. S9, A, D, G). The simulations further demonstrate that the complexes formed are stable, and the ligand positions do not deviate significantly from the crystallographic ones (Fig. 5, B, D, F, H), 
with $\mathrm{C} \alpha \mathrm{RMSD}$ values less than $2.4 \AA$ and an overall ligand RMSD less than $3.5 \AA$ (Fig. 5, I, J, K, L and fig. S9).

Calpain inhibitor XII, UAWJ246 and UAWJ248 are ketoamides having a ketone carbonyl compared to the aldehyde group in calpain inhibitor II and UAWJ247. Calpain inhibitor XII forms hydrogen bond interactions with residues His41, Gly143, Ser144, Cys145, His164 and Glu166 (Fig. 5, C and $\mathrm{D}$ ). The $\mathrm{P} 1$ pyridinyl group is positioned in the $\mathrm{S} 1$ region and forms a hydrogen bond with His163. Compared to calpain inhibitor XII, in UAWJ246 the pyrrolidone substitution occupies the S1 subsite instead of (2-pyridinyl)methyl in calpain inhibitor XII, leading to additional stabilizing hydrogen bonds as described previously. In addition, the small cyclopropyl group in UAWJ246 fits in S1' subsite, avoiding steric repulsions with S1' subsite amino acids as seen in the MD simulation trajectory with calpain inhibitor XII. These changes resulted in a potency enhancement by 100 -fold, i.e., from $0.45 \mu \mathrm{M}$ for calpain inhibitor XII to $0.045 \mu \mathrm{M}$ for UAWJ246. In UAWJ248 the length of the peptide was increased by adding a leucine between P2 Leu and Cbz group and additional lipophilic contacts with P168 are observed (Fig. 5, E, F, G, H) but the activity remained unchanged. Two inhibitor-bound complexes are shown for UAWJ246 (pose 1 and pose 2) (fig. S9, A-C and D-F) and for UAWJ248 (pose 1 and pose 2) (Fig. 5, E, F, G, H), which correspond to different protomers. Minor differences are observed in the hydrogen bonding interactions between the two binding cavities in each protomer, reflecting the dynamic nature of the complexes. For example, a hydrogen bond with His41 was observed in UAWJ246 pose 1 (fig. S9A), while in UAWJ246 pose 2 a hydrogen bond with Asn142 was observed (fig. S9D). Similarly, hydrogen bonds with His41 and Thr190 were observed in UAWJ248 pose 1 (Fig. 5E), and a hydrogen bond with Ser144 was observed in UAWJ248 in pose 2 (Fig. 5G).

Compared to calpain inhibitor II (Fig. 5, A-B), in UAWJ247, which also has an aldehyde warhead, the methionine P1 substituent was changed to pyrrolidone and additional hydrogen bonding interactions are formed. UAWJ247 forms important hydrogen bonding interactions between the P1 2-pyrrolidinone NH group and E166 side chain, and peptidic carbonyl of Phe140 (fig. S9G), in addition to the hydrogen bonds with Gly143, Ser144, Cys145, His164, Glu189. Furthermore, the P2 benzyl group in UAWJ247 fits better in the S2 subsite than the isopropyl from calpain inhibitor II, resulting in new van der Waals interactions with Met49, His41, Met165 (fig. S9G). These additional stabilizing interactions reduce the $\mathrm{IC}_{50}$ against SARS-CoV-2 $\mathrm{M}^{\text {pro }}$ by 23fold, i.e., from $0.97 \mu \mathrm{M}$ in calpain inhibitor II to $0.042 \mu \mathrm{M}$ in UAWJ247.

The RMSF values for the atoms in the P1 substitution of UAWJ246 (21-27), 247 (4-10), and 248 (29-35) were smaller than that from the corresponding atoms of calpain inhibitors II (1-4) and XII (27-34) (fig. S10), suggesting the pyrrolidone substitution is preferred over methionine side chain and the (2-pyridinyl)methyl, although both of which are also tolerated at the S1 pocket.

\section{Cellular antiviral activity and cytotoxicity of GC-376 analogs}

To profile the antiviral activity of the GC-376 analogs UAWJ246, 247, and 248, we first tested their cellular cytotoxicity against multiple cell lines. All three compounds were not toxic to these cell lines with $\mathrm{CC}_{50}$ values greater than 100 $\mu \mathrm{M}$ in most cases (Table $\mathbf{S} 2$ ). As such, we set the highest drug concentration as $30 \mu \mathrm{M}$ or $100 \mu \mathrm{M}$ in the antiviral assay. The antiviral activity of GC-376 analogs was tested in both the immunofluorescence assay and plaque assay using the wildtype SARS-CoV-2 virus. GC-376 was included as a positive control. In the immunofluorescence assay, GC-376, UAWJ246, UAWJ247, and UAWJ248 inhibited the viral replication in a dose-response manner with $\mathrm{EC}_{50}$ values of $1.50 \pm 0.42 \mu \mathrm{M}, 15.13 \pm 6.44 \mu \mathrm{M}, 6.81 \pm 0.65 \mu \mathrm{M}$, and $20.49 \pm$ $3.71 \mu \mathrm{M}$, respectively (Fig. 6, A-D and I). In the plaque assay, GC-376, UAWJ246, UAWJ247, and UAWJ248 inhibited the viral replication with $\mathrm{EC}_{50}$ values of $0.48 \pm 0.29 \mu \mathrm{M}$, $4.61 \pm 3.60 \mu \mathrm{M}, 2.06 \pm 0.93 \mu \mathrm{M}$, and $11.1 \pm 4.2 \mu \mathrm{M}$, respectively (Fig. 6, E-H and J). Overall, all three GC-376 analogs UAWJ246, UAWJ247, and UAWJ248 had confirmed antiviral activity in cell culture. Comparing $\mathrm{M}^{\text {pro }}$ binding and anti-viral potency among the GC-376 analogs, it appears that the aldehyde warhead may be more suitable for cell-based activities than the $\alpha$-ketoamide. While the terminal groups of UAWJ248 may enhance the enzymatic inhibition potency of GC-376 by simultaneously occupying both S3 and S4 subpockets, the weaker cellular antiviral activity of UAWJ248 might be due to decreased cellular permeability or increased metabolic degradation. In addition, as shown by our previous study, the calpain inhibitors demonstrated more potent antiviral activity than GC-376 despite showing weaker binding affinity against $\mathrm{M}^{\text {pro }}$ in vitro (15), consistent with our hypothesis of synergistic inhibition of cathepsin $\mathrm{L}$ and $\mathrm{M}^{\text {pro }}$.

The ongoing COVID-19 pandemic needs an immediate intervention. If the previous SARS-CoV and MERS-CoV outbreaks are not severe enough to attract the attention from the scientific community, the current COVID-19 outbreak is a timely reminder of the threat of coronavirus. Encouraging progress has been made in developing antivirals and vaccines against SARS-CoV-2, such as remdesivir. However, despite the proof-reading function of the SARS-CoV-2 RdRp, SARSCoV-2 continues to mutate, which will inevitably lead to resistance development. Drug resistance has been evolved in cell culture against remdesivir using a model coronavirus, the murine hepatitis virus (MHV) (38), raising concerns for the monotherapy of remdesivir. As such, new drugs with distinct 
mechanisms of action are needed.

The coronavirus $\mathrm{M}^{\text {pro }}\left(3 \mathrm{CL}^{\text {pro }}\right)$ has long been pursued as a promising antiviral drug target (12). The unique feature of $\mathrm{M}^{\mathrm{pro}}$ is its stringent preference for the glutamine residue at the P1 position, while no known host protease has such preference. Accordingly, the majority of $\mathrm{M}^{\text {pro }}$ inhibitors are designed to contain a glutamine mimetic at the P1 position such as pyrrolidone or 2-piperidinone. One of the most advanced lead compounds in this class is GC-376, an investigational veterinary drug that is currently being developed to treat feline infectious peritonitis. GC-376 has optimal in vivo pharmacokinetic properties and in vivo antiviral efficacy in FIPD infection cat model $(39,40)$. Our earlier study, coupled with an independent study from Vuong et al., showed that GC$\mathbf{3 7 6}$ can similarly inhibit the enzymatic activity of SARS-CoV$2 \mathrm{M}^{\mathrm{pro}}$ and the viral replication of SARS-CoV-2 in cell culture (28). While this result is expected, our study also identified three additional non-conventional hits, Boceprevir, calpain inhibitors II and XII (15). These three compounds differ from known $\mathrm{M}^{\text {pro }}$ inhibitors in that they contain hydrophobic substitutions at the P1 site, challenging the notion that hydrophilic glutamine mimetics are required for potent inhibition. Intrigued by this finding, we pursued to solve the X-ray crystal structures of SARS-CoV-2 $\mathrm{M}^{\text {pro }}$ with boceprevir and calpain inhibitors II and XII. During this process, the X-ray crystal structures of SARS-CoV-2 $\mathrm{M}^{\text {pro }}$ in complex with boceprevir were released in PDB (PDB ID: 7BRP and 6WNP), and we therefore shifted our focus to calpain inhibitors II and XII. The binding pose of calpain inhibitor II in the active site of $\mathrm{M}^{\text {pro }}$ is consistent with other peptidomimetic inhibitors, where the methionine and leucine side chains occupy the S1 and S2 pockets, respectively. The methionine sulfur atom forms a hydrogen bond with the side chain imidazole of His163. In contrast, calpain inhibitor XII binds to the $\mathrm{M}^{\text {pro }}$ active site in an inverted conformation, projecting the pyridine instead of the norvaline residue in the S1 pocket. Again, the nitrogen from the pyridine forms a hydrogen bond with the side chain imidazole of His163. Collectively, these two structures suggest that His163 residue at the S1 pocket represents a binding hot spot for $\mathrm{M}^{\text {pro }}$ inhibitors, and that the pyridine ring is a suitable side chain to engineer potent interactions with the S1 subsite. The ligand plasticity of the P1 site suggests that it is feasible to design dual inhibitors targeting both the viral $\mathrm{M}^{\text {pro }}$ and other important proteases, such as cathepsin L. Cathepsin L has been identified as a critical host-protease for the SARS-CoV-2 cell entry. It plays an essential role in mediating the activation of the viral spike protein, thereby triggering membrane fusion and viral RNA release $(20,22)$. Although the antiviral potency of cathepsin $\mathrm{L}$ inhibitors has been demonstrated against coronaviruses including SARS-CoV-2 in several studies, the in vivo antiviral efficacy of cathepsin L inhibitors is not known. One potential concern is that the coronavirus spike protein can also be activated by other host proteases including trypsin, calpain, and TMPRSS2. Therefore, it is not clear whether inhibition of cathepsin $\mathrm{L}$ alone will be sufficient to completely stop viral replication in vivo. In this regard, a dual inhibitor design strategy that targets both the viral $\mathrm{M}^{\text {pro }}$ and host cathepsin $\mathrm{L}$ has certain advantages. First, compared to mono-specific $\mathbf{M}^{\text {pro }}$ inhibitors, dual inhibitors might have a higher genetic barrier to drug resistance as they also target the host cathepsin $\mathrm{L}$. Second, compared to mono-specific cathepsin L inhibitors, dual inhibitors can lead to complete inhibition of viral replication as it targets the essential viral protein $\mathrm{M}^{\text {pro }}$.

Comparing X-ray crystal structures of SARS-CoV-2 $\mathrm{M}^{\text {pro }}$ in complex with UAWJ246, UAWJ247, and UAWJ248 to the complex structure of GC-376, we can conclude that 1) the P1' substitution does not contribute significantly to the potency of drug binding; 2) the P2 position prefers hydrophobic substitutions such as the leucine and phenylalanine side chains. Previous studies also demonstrate the cyclopropyl and cyclohexyl groups can be similarly accommodated (17, $18)$; 3) the $\mathrm{P} 3$ and $\mathrm{P} 4$ positions prefer to be hydrophobic substitutions. However, these two positions, especially P3, may not be as important as the P1 and P2 substitutions, but favorable interactions with S3 and S4 subpockets can still contribute to the potency of inhibitor binding; 4) while the unique conformation of calpain inhibitor XII demonstrates the versatility of the $\alpha$-ketoamide adduct formation, comparing the potent antiviral activities of the GC-376 analogs with different warheads indicate that aldehyde-based compounds may be better suited for cell-based activity.

In summary, the structure-activity relationship of $\mathrm{M}^{\text {pro }}$ inhibitors revealed by the X-ray crystal structures and enzymatic assays described herein can be used to guide lead optimization. P1 substitution and the reactive warhead contribute significantly to the drug binding potency, followed by P2 substitution. While P1', P3 and P4 substitutions are less essential, they can be optimized for inhibition against other proteases important for SARS-CoV-2 entry/replication and to improve their pharmacokinetic properties.

\section{MATERIALS AND METHODS \\ Cell lines and viruses}

Human rhabdomyosarcoma (RD), MDCK, Vero, Huh-7, and HCT-8 cell lines were maintained in Dulbecco's modified Eagle's medium (DMEM) medium; Caco-2 and MRC-5 cell lines were maintained in Eagle's Minimum Essential Medium (EMEM) medium. Both media were supplemented with $10 \%$ fetal bovine serum (FBS) and $1 \%$ penicillin-streptomycin antibiotics. Cells were kept at $37^{\circ} \mathrm{C}$ in a $5 \% \mathrm{CO}_{2}$ atmosphere. VERO E6 cells (ATCC, CRL-1586) were cultured in Dulbecco's modified Eagle's medium (DMEM), supplemented with 5\% heat inactivated $\mathrm{FBS}$ in a $37^{\circ} \mathrm{C}$ incubator with $5 \% \mathrm{CO}_{2}$. SARS- 
CoV-2, isolate USA-WA1/2020 (NR-52281), was obtained through BEI Resources and propagated once on VERO E6 cells before it was used for this study. Studies involving the SARS-CoV-2 were performed at the UTHSCSA biosafety level3 laboratory by personnel wearing powered air purifying respirators.

\section{Protein expression and purification}

SARS CoV-2 main protease ( $\mathrm{M}^{\text {pro }}$ or $3 \mathrm{CL}$ ) gene from strain BetaCoV/Wuhan/WIV04/2019 was ordered from GenScript (Piscataway, NJ) in the pET29a(+) vector with $E$. coli codon optimization. The expression and purification of His-tagged

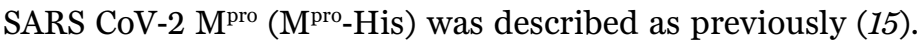
Briefly, the $\mathrm{M}^{\text {pro }}$ gene was inserted into pET29a(+) with NdeI/XhoI digestion sites. The N-terminal methionine was removed by $E$. Coli methionine aminopeptidase. There are extra $\mathrm{LEHHHHHH}$ residues at the $\mathrm{C}$ terminus. The protein sequence for the C-terminal His-tagged SARS-CoV-2 $\mathrm{M}^{\text {pro }}$ is:

SGFRKMAFPSGKVEGCMVQVTCGTTTLNGLWLDDVVYCPR HVICTSEDMLNPNYEDLLIRKSNHNFLVQAGNVQLRVIGHS MQNCVLKLKVDTANPKTPKYKFVRIQPGQTFSVLACYNGSP SGVYQCAMRPNFTIKGSFLNGSCGSVGFNIDYDCVSFCYMH HMELPTGVHAGTDLEGNFYGPFVDRQTAQAAGTDTTITVN VLAWLYAAVINGDRWFLNRFTTTLNDFNLVAMKYNYEPLT QDHVDILGPLSAQTGIAVLDMCASLKELLQNGMNGRTILGS ALLEDEFTPFDVVRQCSGVTFQLEHHHНHН.

For HM-M $\mathrm{M}^{\text {pro }}$ expression and purification, the SARS-CoV$2 \mathrm{M}^{\text {pro }}$ gene from strain BetaCoV/Wuhan/WIV04/2019 GenScript (Piscataway, NJ, USA) was inserted into pETGSTSUMO vector. The plasmid was transformed into Rosetta(DE3) pLysS Competent Cells (Novagen). A single colony was picked for overnight growth to inoculate $50 \mathrm{~mL}$ of $\mathrm{LB}$ broth with $50 \mu \mathrm{g} / \mathrm{mL}$ kanamycin and $35 \mu \mathrm{g} / \mathrm{mL}$ chloramphenicol. $10 \mathrm{~mL}$ of the overnight culture was used to inoculate $1 \mathrm{~L}$ of LB broth with $50 \mu \mathrm{g} / \mathrm{mL}$ kanamycin and $35 \mu \mathrm{g} / \mathrm{mL}$ chloramphenicol. The $1 \mathrm{~L}$ culture was grown at $250 \mathrm{RPM}, 37^{\circ} \mathrm{C}$ until OD reached 0.6 0.8. Expression was then induced with 0.5 $\mathrm{mM}$ IPTG at $250 \mathrm{RPM}, 20^{\circ} \mathrm{C}$ overnight. The culture was centrifuged at $5,000 \mathrm{x} \mathrm{g}$ for $20 \mathrm{~min}$ and the resulting pellet was resuspended in $30 \mathrm{~mL}$ of the lysis buffer $(20 \mathrm{mM}$ Tris- $\mathrm{HCl} \mathrm{pH}$ $8.4,300 \mathrm{mM} \mathrm{NaCl}, 10 \%$ glycerol, and $20 \mathrm{mM}$ imidazole). These cells were lysed by sonication on a 10 second sonication/ 15 second rest cycle for a total of 15 minutes at an amplitude of 6 . The lysate was centrifuged at $40,000 \times \mathrm{g}$ for 45 minutes at $4{ }^{\circ} \mathrm{C}$ and the supernatant was filtered, then loaded onto a HiTrap HP column. The column was washed with lysate buffer and the protein was then eluted by linear gradient of imidazole. The peak of the protein was pooled and concentrated. The protein was then diluted in ULP1 cleavage buffer (20 mM Tris pH 8.0, $100 \mathrm{mM} \mathrm{NaCl}$ and 10\% glycerol).
The protease ULP1 was added at 1:20 ratio with incubation at $20^{\circ} \mathrm{C}$ overnight. The sample was loaded to a HisTrap HP column and the flow through containing the HM-M ${ }^{\text {pro }}$ was collected. The HM-M ${ }^{\text {pro }}$ was concentrated and loaded to Superdex 200/16 equilibrated with $20 \mathrm{mM}$ Tris pH 8.0, $250 \mathrm{mM}$ $\mathrm{NaCl}$. The peak fractions were pooled and concentrated to 10 $\mathrm{mg} / \mathrm{mL}$ and flash-frozen with liquid nitrogen. The purity of the protein was evaluated by SDS-PAGE. The protein sequence for the SARS-CoV-2 HM-M ${ }^{\text {pro }}$ is:

HMSGFRKMAFPSGKVEGCMVQVTCGTTTLNGLWLDDVVY CPRHVICTSEDMLNPNYEDLLIRKSNHNFLVQAGNVQLRVI GHSMQNCVLKLKVDTANPKTPKYKFVRIQPGQTFSVLACYN GSPSGVYQCAMRPNFTIKGSFLNGSCGSVGFNIDYDCVSFCY MHHMELPTGVHAGTDLEGNFYGPFVDRQTAQAAGTDTTI TVNVLAWLYAAVINGDRWFLNRFTTTLNDFNLVAMKYNYE PLTQDHVDILGPLSAQTGIAVLDMCASLKELLQNGMNGRTI LGSALLEDEFTPFDVVRQCSGVTFQ.

The expression and purification of SARS CoV-2 $\mathrm{M}^{\text {pro }}$ with unmodified $\mathrm{N}$ - and C-termini $\left(\mathrm{M}^{\text {pro }}\right)$. SARS CoV-2 $\mathrm{M}^{\text {pro }}$ gene was subcloned from pET29a(+) to pE-SUMO vector according to manufacturer's protocol (LifeSensors Inc, Malvern PA). The forward primer with BsaI site is: GCGGTCTCAAGGTTCAGGATTTAGGAAGATGGCATTTCC; the reverse primer with $\mathrm{XbaI}$ site is: GCTCTAGATTACTGAAAGGTCACGCCGCTGCATTGACG. After removal of SUMO tag with SUMO protease, there is no any extra residues at either $\mathrm{N}$ - or C-termini. pE-SUMO plasmid with SARS CoV-2 Main protease gene $\left(\mathrm{M}^{\text {pro }}\right)$ was transformed into BL21(DE3) cells with kanamycin selection. A single colony was picked to inoculate $10 \mathrm{ml} \mathrm{LB}$ media and was cultured $37^{\circ} \mathrm{C}$ overnight. This $10 \mathrm{ml}$ culture was added to 1 liter LB media and grown to around OD 600 of 0.8 . This culture was cooled on ice for $15 \mathrm{~min}$, then induced with $0.5 \mathrm{mM}$ IPTG. Induced cultures were incubated at $18^{\circ} \mathrm{C}$ for an additional 24 hours and then harvested, lysed same way as Histagged $\mathrm{M}^{\text {pro }}$ protein.(15) The supernatant was incubated with Ni-NTA resin for overnight at $4^{\circ} \mathrm{C}$ on a rotator. The Ni-NTA resin was thoroughly washed with $30 \mathrm{mM}$ imidazole in wash buffer (50 mM Tris [pH 7.0], $150 \mathrm{mM} \mathrm{NaCl}, 2 \mathrm{mM}$ DTT), SUMO-tagged $\mathrm{M}^{\text {pro }}$ was eluted from Ni-NTA with $300 \mathrm{mM}$ imidazole. Eluted SUMO-tagged $\mathrm{M}^{\text {pro }}$ was dialyzed against 100fold volume dialysis buffer (50 mM Tris [pH 7.0], $150 \mathrm{mM}$ $\mathrm{NaCl}, 2 \mathrm{mM}$ DTT) in a 10,000-molecular-weight-cutoff dialysis tubing. After dialysis, SUMO-tagged $\mathrm{M}^{\text {pro }}$ was incubated with SUMO protease 1 at $4^{\circ} \mathrm{C}$ for overnight, and SUMO tag was removed by application of another round of Ni-NTA resin. The purity of the protein was confirmed with SDS-page gel. The protein sequence for the native SARS-CoV-2 $\mathrm{M}^{\text {pro }}$ is:

\section{SGFRKMAFPSGKVEGCMVQVTCGTTTLNGLWLDDVVYCPR}


HVICTSEDMLNPNYEDLLIRKSNHNFLVQAGNVQLRVIGHS MQNCVLKLKVDTANPKTPKYKFVRIQPGQTFSVLACYNGSP SGVYQCAMRPNFTIKGSFLNGSCGSVGFNIDYDCVSFCYMH HMELPTGVHAGTDLEGNFYGPFVDRQTAQAAGTDTTITVN VLAWLYAAVINGDRWFLNRFTTTLNDFNLVAMKYNYEPLT QDHVDILGPLSAQTGIAVLDMCASLKELLQNGMNGRTILGS ALLEDEFTPFDVVRQCSGVTFQ.

The expression and purification of SARS CoV-2 papainlike protease $\left(\mathrm{PL}^{\mathrm{pro}}\right)$. SARS CoV-2 papain-like protease $\left(\mathrm{PL}^{\mathrm{pro}}\right)$ gene (ORF lab 1564 to 1876) from strain BetaCoV/Wuhan/WIV04/2019 was ordered from GenScript (Piscataway, $\mathrm{NJ})$ in the pET28b(+) vector with $E$. coli codon optimization. The SARS CoV-2 PL ${ }^{\text {pro }}$ gene was inserted into pET28b(+) with $\mathrm{NcoI} / \mathrm{XhoI}$ sites. The expression and purification procedures are similar to that of $\mathrm{M}^{\text {pro-His }}$-Hotein as described above, except that the lysis buffer and Ni-NTA wash and elution buffer are in pH7.5 (50 mM Tris [pH 7.5], $150 \mathrm{mM} \mathrm{NaCl}, 2 \mathrm{mM}$ DTT). The N-terminal methionine was removed by E. coli methionine aminopeptidase based on our mass spectrum result. There are extra LEHHHHHH residues at C-terminal.

The final protein sequence for the SARS-CoV-2 PL ${ }^{\text {pro }}$ is:

GEVRTIKVFTTVDNINLHTQVVDMSMTYGQQFGPTYLDGA DVTKIKPHNSHEGKTFYVLPNDDTLRVEAFEYYHTTDPSFL GRYMSALNHTKKWKYPQVNGLTSIKWADNNCYLATALLTL QQIELKFNPPALQDAYYRARAGEAANFCALILAYCNKTVGE LGDVRETMSYLFQHANLDSCKRVLNVVCKTCGQQQTTLKG VEAVMYMGTLSYEQFKKGVQIPCTCGKQATKYLVQQESPFV MMSAPPAQYELKHGTFTCASEYTGNYQCGHYKHITSKETLY CIDGALLTKSSEYKGPITDVFYKENSYTTTIKLEHHHHHH.

Human liver Cathepsin L was purchased from EMD Millipore (Cat \# 219402).

\section{Peptide synthesis}

The SARS-CoV-2 $\mathrm{M}^{\text {pro }}$ FRET substrate DabcylKTSAVLQ/SGFRKME(Edans) was synthesized as described before (15). The SARS-CoV-2 PL ${ }^{\text {pro }}$ FRET substrate DabcylFTLRGG/APTKV(Edans) was synthesized by solid-phase synthesis through iterative cycles of coupling and deprotection using the previously optimized procedure (41). Specifically, chemmatrix rink-amide resin was used. Typical coupling condition was 5 equiv of amino acid, 5 equiv of HATU, and 10 equiv of DIEA in DMF for $5 \mathrm{~min}$ at $80^{\circ} \mathrm{C}$. For deprotection, $5 \%$ piperazine plus $0.1 \mathrm{M} \mathrm{HOBt}$ were used and the mixture was heated at $80^{\circ} \mathrm{C}$ for $5 \mathrm{~min}$. The peptide was cleaved from the resin using $95 \%$ TFA, $2.5 \%$ Tris, $2.5 \% \mathrm{H}_{2} \mathrm{O}$ and the crude peptide was precipitated from ether after removal of TFA. The final peptide was purified by preparative HPLC. The purify and identify of the peptide were confirmed by analytical HPLC (> 98\% purity) and mass spectrometry. $[\mathrm{M}+2]^{2+}$ calculated 888.04 , detected 888.80 .

\section{Compound synthesis and characterization}

Details for the synthesis procedure (fig. S1) and characterization for compounds UAWJ257, UAWJ246, UAWJ247, and UAWJ248 can be found in the supplementary information.

\section{Native Mass Spectrometry}

Prior to analysis, the protein was buffer exchanged into 0.2 $\mathrm{M}$ ammonium acetate ( $\mathrm{pH} 6.8$ ) and diluted to $10 \mu \mathrm{M}$. DTT was dissolved in water and prepared at a $400 \mathrm{mM}$ stock. Each ligand was dissolved in ethanol and diluted to $10 \mathrm{X}$ stock concentrations. The final mixture was prepared by adding $4 \mu \mathrm{L}$ protein, $0.5 \mu \mathrm{L}$ DTT stock, and $0.5 \mu \mathrm{L}$ ligand stock for final concentration of $4 \mathrm{mM}$ DTT and $8 \mu \mathrm{M}$ protein. Final ligand concentrations were $10 \mu \mathrm{M}$. The mixtures were then incubated for $10 \mathrm{~min}$ at room temperature prior to analysis. Each sample was mixed and analyzed in triplicate.

Native mass spectrometry (MS) was performed using a QExactive HF quadrupole-Orbitrap mass spectrometer with the Ultra-High Mass Range research modifications (Thermo Fisher Scientific). Samples were ionized using nano-electrospray ionization in positive ion mode using $1.0 \mathrm{kV}$ capillary voltage at a $150^{\circ} \mathrm{C}$ capillary temperature. The samples were all analyzed with a 1,000-25,000 m/z range, the resolution set to 30,000 , and a trapping gas pressure set to 3 . Between 10 and $50 \mathrm{~V}$ of source fragmentation was applied to all samples to aid in desolvation. Data were deconvolved and analyzed with UniDec (42).

\section{Enzymatic assays}

The main protease $\left(\mathrm{M}^{\text {pro }}\right)$ enzymatic assays were carried out exact as previously described in $\mathrm{pH} 6.5$ reaction buffer containing $20 \mathrm{mM}$ HEPES pH 6.5, $120 \mathrm{mM} \mathrm{NaCl}, 0.4 \mathrm{mM}$ EDTA, $20 \%$ glycerol and $4 \mathrm{mM}$ DTT (15).

The SARS-CoV-2 papain-like protease $\left(\mathrm{PL}^{\mathrm{pro}}\right)$ enzymatic assays were carried out as follows: the assay was assembled in 96-well plates with $100 \mu \mathrm{l}$ of $200 \mathrm{nM} \mathrm{PL}^{\text {Pro }}$ protein in $\mathrm{PL}^{\text {Pro }}$ reaction buffer (50 mM HEPES, pH7.5, 0.01\% triton-100 and $5 \mathrm{mM}$ DTT). Then $1 \mu \mathrm{l}$ testing compound at various concentrations was added to each well and incubated at $30^{\circ} \mathrm{C}$ for 30 $\mathrm{min}$. The enzymatic reaction was initiated by adding $1 \mu \mathrm{l}$ of 1 mM FRET substrate (the final substrate concentration is 10 $\mu \mathrm{M})$. The reaction was monitored in a Cytation 5 image reader with filters for excitation at $360 / 40 \mathrm{~nm}$ and emission at $460 / 40 \mathrm{~nm}$ at $30^{\circ} \mathrm{C}$ for 1 hour. The initial velocity of the enzymatic reaction with and without testing compounds was calculated by linear regression for the first $15 \mathrm{~min}$ of the kinetic progress curve. The $\mathrm{IC}_{50}$ values were calculated by plotting the initial velocity against various concentrations of testing compounds with a dose response function in Prism 8 
software.

The cathepsin L enzymatic assay was carried out as follows: human liver cathepsin L (EMD Millipore 219402) was activated by incubating at reaction buffer $(20 \mathrm{mM}$ sodium acetate, $1 \mathrm{mM}$ EDTA and $5 \mathrm{mM}$ DTT pH5.5) for $30 \mathrm{~min}$ at $30^{\circ} \mathrm{C}$. Upon activation, the assay was assembled in 96-well plates with $100 \mu \mathrm{l}$ of $300 \mathrm{pM}$ cathepsin L protein in cathepsin L reaction buffer. Then $1 \mu \mathrm{l}$ testing compound at various concentrations was added to each well and incubated at $30^{\circ} \mathrm{C}$ for 30 $\mathrm{min}$. The enzymatic reaction was initiated by adding $1 \mu$ of $100 \mu$ M FRET substrate Z-Phe-Arg-AMC (the final substrate concentration is about $1 \mu \mathrm{M}$ ). The reaction was monitored in a Cytation 5 image reader with filters for excitation at 360/40 $\mathrm{nm}$ and emission at $460 / 40 \mathrm{~nm}$ at $30^{\circ} \mathrm{C}$ for 1 hour. The $\mathrm{IC}_{50}$ values were calculated as described in above section.

\section{Differential scanningfluorimetry (DSF)}

The thermal shift binding assay (TSA) was carried out using a Thermal Fisher QuantStudio ${ }^{\mathrm{TM}} 5$ Real-Time PCR System as described previously (15). Briefly, $3 \mu \mathrm{M}$ SARS-CoV-2 $\mathrm{M}^{\text {pro }}$ protein in $\mathrm{M}^{\text {pro }}$ reaction buffer (20 mM HEPES, pH 6.5, $120 \mathrm{mM}$ $\mathrm{NaCl}, 0.4 \mathrm{mM}$ EDTA, $4 \mathrm{mM}$ DTT and $20 \%$ glycerol) was incubated with testing compounds at $30^{\circ} \mathrm{C}$ for $30 \mathrm{~min}$. 1X SYPRO orange dye was added and fluorescence of the well was monitored under a temperature gradient range from $20^{\circ} \mathrm{C}$ to $90^{\circ} \mathrm{C}$ with $0.05^{\circ} \mathrm{C} / \mathrm{s}$ incremental step.

\section{Cytotoxicity measurement}

Evaluation of the cytotoxicity of compounds were carried out using the neutral red uptake assay (43). Briefly, 80,000 cells/mL of the tested cell lines were dispensed into 96 -well cell culture plates at $100 \mu \mathrm{L} /$ well. Twenty-four hours later, the growth medium was removed and washed with $150 \mu \mathrm{L}$ PBS buffer. $200 \mu \mathrm{L}$ fresh serum-free medium containing serial diluted compounds was added to each well. After incubating for 5 days at $37^{\circ} \mathrm{C}$, the medium was removed and replaced with $100 \mu \mathrm{L}$ DMEM medium containing $40 \mu \mathrm{g} / \mathrm{mL}$ neutral red and incubated for $2-4$ hours at $37^{\circ} \mathrm{C}$. The amount of neutral red taken up was determined by measuring the absorbance at $540 \mathrm{~nm}$ using a Multiskan FC Microplate Photometer (Fisher Scientific). The $\mathrm{CC}_{50}$ values were calculated from bestfit dose response curves with variable slope in Prism 8.

\section{Molecular dynamics simulations}

MD simulations were carried out to the covalently bound calpain inhibitor II, calpain inhibitor XII, UAWJ246, UAWJ247, UAWJ248 with SARS-CoV-2 $\mathrm{M}^{\text {pro }}$ corresponding to PDB ID 6XA4 (monomer), PDB ID 6XFN (monomer), PDB ID 6XBG (dimer), PDB ID 6XBH (monomer), PDB ID 6XBI (dimer) prepared as described previously (44). The most favored protonation states of ionizable residues (D, E, R, K and $\mathrm{H}$ ) at $\mathrm{pH} 7$ were assigned using Maestro. The protonation states of the histidines in the binding region were set to $\delta$ position in order to contribute to the stabilization of complexes. Crystal waters were kept. All hydrogens atoms of the protein complex complex were minimized with the OPLS2005 force field (45) by means of Maestro/Macromodel (Schrodinger 2017-1) using a distance-dependent dielectric constant of 4.0. The molecular mechanics minimization was performed with a conjugate gradient (CG) method and a root mean square of the energy gradient (threshold) value of 0.005 $\mathrm{kJ} \AA^{-1} \mathrm{~mol}^{-1}$ was used as the convergence criterion.

Each complex was solvated using the TIP3P (46) water model. Using the "System Builder" utility of Schrodinger Desmond v.11.1 each complex was embedded in an orthorhombic water box extending beyond the solute $15 \AA$ in x,y-plane and z-direction. $\mathrm{Na}^{+}$and $\mathrm{Cl}^{-}$ions were placed in the water phase to neutralize the systems and to reach the experimental salt concentration of $0.150 \mathrm{M} \mathrm{NaCl}$. Each complex consists of c.a. 305 amino acid residues and 4,653 atoms and $\sim 18,600$ water residues (55,700 water atoms) or c.a. $\sim 60,350$ atoms for the monomer proteins and $\sim 29,700$ water residues $(89,200$ water atoms) for the dimer proteins, i.e., 98,000 atoms.

The OPLS2005 force field $(47,48)$ was used to model all protein and ligand interactions and lipids. The particle mesh Ewald method (PME) $(49,50)$ was employed to calculate long-range electrostatic interactions with a grid spacing of $0.8 \AA$. Van der Waals and short range electrostatic interactions were smoothly truncated at $9.0 \AA$. The Nose-Hoover thermostat was utilized to maintain a constant temperature in all simulations, and the Martyna-Tobias-Klein barostat was used to control the pressure. Periodic boundary conditions were applied $(68 \times 95 \times 97) \AA^{3}$ for the monomers and $(105 \times 106 \times 96) \AA^{3}$ for the dimers. The equations of motion were integrated using the multistep RESPA integrator (51) with an inner time step of 2 fs for bonded interactions and non-bonded interactions within a cutoff $9 \AA$. An outer time step of 6.0 fs was used for non-bonded interactions beyond the cut-off.

Each system was equilibrated in MD simulations with a default protocol for water-soluble proteins provided in Desmond, which consists of a series of restrained MD simulations designed to relax the system, while not deviating substantially from the initial coordinates.

The first simulation was a Brownian dynamics run for 100 ps at a temperature of $10 \mathrm{~K}$ in the NVT (constant number of particles, volume, and temperature) ensemble with solute heavy atoms restrained with a force constant of $50 \mathrm{kcal} \mathrm{mol}$ $\AA^{-2}$. The Langevin thermostat (52) was applied in the NVT ensemble and a MD simulation for $12 \mathrm{ps}$ with solute heavy atoms restrained with a force constant of $50 \mathrm{kcal} \mathrm{mol} \AA^{-2}$. The velocities were randomized and MD simulation for 12 ps was performed in the NPT ensemble and a Berendsen barostat (53) with solute heavy atoms equally restrained at $10 \mathrm{~K}$ and 
another one at $300 \mathrm{~K}$. The velocities were again randomized and unrestrained MD simulation for $24 \mathrm{ps}$ was performed in the NPT ensemble. The above-mentioned equilibration was followed by 100ns simulation without restrains. Two MD simulations for each system were performed, one in in workstation with GTX 970, and using the GPU implementation of the MD simulations code, and one in ARIS-supercomputer system with cpu-cores. The visualization of produced trajectories and structures was performed using the programs Chimera (54) and VMD.

\section{Immunofluorescence assay}

Vero E6 cells in 96-well plates (Corning) were infected with SARS-CoV-2 (USA-WA1/2020 isolate) at MOI of 0.05 in DMEM supplemented with $1 \%$ FBS. Immediately before the viral inoculation, the tested compounds in a three-fold dilution concentration series were also added to the wells in triplicate. The infection proceeded for 48 hours without the removal of the viruses or the compounds. The cells were then fixed with $4 \%$ paraformaldehyde, permeabilized with $0.1 \%$ Triton-100, blocked with DMEM containing 10\% FBS, and stained with a rabbit monoclonal antibody against SARSCoV-2 NP (GeneTex, GTX635679) and an Alexa Fluor 488conjugated goat anti-mouse secondary antibody (ThermoFisher Scientific). Hoechst 33342 was added in the final step to counterstain the nuclei. Fluorescence images of approximately ten thousand cells were acquired per well with a 10x objective in a Cytation 5 (BioTek). The total number of cells, as indicated by the nuclei staining, and the fraction of the infected cells, as indicated by the NP staining, were quantified with the cellular analysis module of the Gen5 software (BioTek).

\section{Plaque assay}

Vero E6 cells in 6-well plates (Corning) were infected with SARS-CoV-2 (USA-WA1/2020 isolate) at approximately 40 PFU per well. After 1 hour of incubation at $37^{\circ} \mathrm{C}$, the inoculum was removed and replaced with DMEM containing 1\% FBS, 1.2\% Avicel RC-591 (Dupont) and the tested compounds at different concentrations, in duplicate. After 3 days of infection, the overlay was removed, and the cells were fixed with $4 \%$ paraformaldehyde and stained with $0.2 \%$ crystal violet.

\section{$M^{\text {pro }}$ crystallization and structure determination}

SARS-CoV-2 $\mathrm{M}^{\text {pro }}$ was diluted to $5 \mathrm{mg} / \mathrm{mL}$ and incubated with $1.5 \mathrm{mM}$ of inhibitor at $4^{\circ} \mathrm{C}$ overnight. Samples were centrifuged at $13,000 \times \mathrm{g}$ for $1 \mathrm{~min}$ to remove precipitate. Crystals were grown by mixing the protein-inhibitor sample with an equal volume of crystallization buffer (20\% PEG 3000, $0.2 \mathrm{M}$ $\mathrm{Na}$ Citrate $\mathrm{pH}$ 5.6) in a vapor diffusion, hanging drop apparatus. A cryoprotectant solution of 35\% PEG 3000 and 30\% glycerol was added directly to the drop and soaked for $15 \mathrm{~min}$.
Crystals were then flash frozen in liquid nitrogen for X-ray diffraction.

X-ray diffraction data for the SARS-CoV-2 $\mathrm{M}^{\text {pro }}$ structures were collected on the SBC 19-ID beamline at the Advanced Photon Source (APS) in Argonne, IL, and processed with the HKL3000 software suite (55). The CCP4 versions of MOLREP was used for molecular replacement using a previously solved SARS-CoV-2 $\mathrm{M}^{\text {pro }}$ structure, PDB ID: $7 \mathrm{BRR}$ as a reference model for the dimeric $\mathrm{P} 2{ }_{1} \mathrm{M}^{\text {pro }}$ with UAWJ246 (56). PDB ID $6 \mathrm{YB} 7$ was used as the reference model for the $\mathrm{C} 2$ monomeric $\mathrm{M}^{\text {pro }}$ with calpain inhibitors II and XII and UAWJ247, and the P1 dimeric structure with UAWJ248. PDB ID 6WTT was used as the reference model for the $\mathrm{P}_{2} 21$ trimer with UAWJ246. Rigid and restrained refinements were performed using REFMAC and model building was performed with $\operatorname{COOT}(57,58)$. Protein structure figures were made using PyMOL (Schrödinger, LLC).

\section{REFERENCES AND NOTES}

1. C. Liu, Q. Zhou, Y. Li, L. V. Garner, S. P. Watkins, L. J. Carter, J. Smoot, A. C. Gregg, A. D. Daniels, S. Jervey, D. Albaiu, Research and Development on Therapeutic Agents and Vaccines for COVID-19 and Related Human Coronavirus Diseases. ACS Cent. Sci. 6, 315-331 (2020). doi:10.1021/acscentsci.0c00272 Medline

2. T. Pillaiyar, S. Meenakshisundaram, M. Manickam, Recent discovery and development of inhibitors targeting coronaviruses. Drug Discov. Today 25, 668688 (2020). doi:10.1016/j.drudis.2020.01.015 Medline

3. M. Wang, R. Cao, L. Zhang, X. Yang, J. Liu, M. Xu, Z. Shi, Z. Hu, W. Zhong, G. Xiao, Remdesivir and chloroquine effectively inhibit the recently emerged novel coronavirus (2019-nCoV) in vitro. Cell Res. 30, 269-271 (2020). doi:10.1038/s41422-020-0282-0 Medline

4. R. T. Eastman, J. S. Roth, K. R. Brimacombe, A. Simeonov, M. Shen, S. Patnaik, M. D. Hall, Remdesivir: A Review of Its Discovery and Development Leading to Emergency Use Authorization for Treatment of COVID-19. ACS Cent. Sci. 6, 672683 (2020). doi:10.1021/acscentsci.0c00489 Medline

5. T. P. Sheahan, A. C. Sims, R. L. Graham, V. D. Menachery, L. E. Gralinski, J. B. Case, S. R. Leist, K. Pyrc, J. Y. Feng, I. Trantcheva, R. Bannister, Y. Park, D. Babusis, M. O. Clarke, R. L. Mackman, J. E. Spahn, C. A. Palmiotti, D. Siegel, A. S. Ray, T. Cihlar, R. Jordan, M. R. Denison, R. S. Baric, Broad-spectrum antiviral GS-5734 inhibits both epidemic and zoonotic coronaviruses. Sci. Transl. Med. 9, eaal3653 (2017). doi:10.1126/scitranslmed.aal3653 Medline

6. E. de Wit, F. Feldmann, J. Cronin, R. Jordan, A. Okumura, T. Thomas, D. Scott, T. Cihlar, H. Feldmann, Prophylactic and therapeutic remdesivir (GS-5734) treatment in the rhesus macaque model of MERS-CoV infection. Proc. Natl. Acad. Sci. U.S.A. 117, 6771-6776 (2020). doi:10.1073/pnas.1922083117 Medline

7. T. P. Sheahan, A. C. Sims, S. R. Leist, A. Schäfer, J. Won, A. J. Brown, S. A. Montgomery, A. Hogg, D. Babusis, M. O. Clarke, J. E. Spahn, L. Bauer, S. Sellers, D. Porter, J. Y. Feng, T. Cihlar, R. Jordan, M. R. Denison, R. S. Baric, Comparative therapeutic efficacy of remdesivir and combination lopinavir, ritonavir, and interferon beta against MERS-CoV. Nat. Commun. 11, 222 (2020). do:i:10.1038/s41467-019-13940-6 Medline

8. Y. Wang, V. Anirudhan, R. Du, Q. Cui, L. Rong, RNA-dependent RNA polymerase of SARS-CoV-2 as a therapeutic target. J. Med. Virol. (2020). 10.1002/jmv.26264 Medline

9. T. P. Sheahan, A. C. Sims, S. Zhou, R. L. Graham, A. J. Pruijssers, M. L. Agostini, S. R. Leist, A. Schäfer, K. H. Dinnon 3rd, L. J. Stevens, J. D. Chappell, X. Lu, T. M. Hughes, A. S. George, C. S. Hill, S. A. Montgomery, A. J. Brown, G. R. Bluemling, M. G. Natchus, M. Saindane, A. A. Kolykhalov, G. Painter, J. Harcourt, A. Tamin, N. J. Thornburg, R. Swanstrom, M. R. Denison, R. S. Baric, An orally bioavailable broadspectrum antiviral inhibits SARS-CoV-2 in human airway epithelial cell cultures and multiple coronaviruses in mice. Sci. Transl. Med. 12, eabb5883 (2020). doi:10.1126/scitranslmed.abb5883 Medline 
10. S. Xia, M. Liu, C. Wang, W. Xu, Q. Lan, S. Feng, F. Qi, L. Bao, L. Du, S. Liu, C. Qin, F. Sun, Z. Shi, Y. Zhu, S. Jiang, L. Lu, Inhibition of SARS-CoV-2 (previously 2019$\mathrm{nCoV}$ ) infection by a highly potent pan-coronavirus fusion inhibitor targeting its spike protein that harbors a high capacity to mediate membrane fusion. Cell Res. 30, 343-355 (2020). doi:10.1038/s41422-020-0305-x Medline

11. S. Xia, L. Yan, W. Xu, A. S. Agrawal, A. Algaissi, C. K. Tseng, Q. Wang, L. Du, W. Tan, I. A. Wilson, S. Jiang, B. Yang, L. Lu, A pan-coronavirus fusion inhibitor targeting the HR1 domain of human coronavirus spike. Sci. Adv. 5, eaav4580 (2019). doi:10.1126/sciadv.aav4580 Medline

12. T. Pillaiyar, M. Manickam, V. Namasivayam, Y. Hayashi, S. H. Jung, An Overview of Severe Acute Respiratory Syndrome-Coronavirus (SARS-CoV) 3CL Protease Inhibitors: Peptidomimetics and Small Molecule Chemotherapy. J. Med. Chem. 59, 6595-6628 (2016). doi:10.1021/acs.jmedchem.5b01461 Medline

13. W. Rut, K. Groborz, L. Zhang, X. Sun, M. Zmudzinski, B. Pawlik, W. Młynarski, R. Hilgenfeld, M. Drag, Substrate specificity profiling of SARS-CoV-2 $M<$ sup $>$ pro</sup $>$ protease provides basis for anti-COVID-19 drug design. bioRxiv, 2020.2003.2007.981928 (2020).

14. S. Ullrich, C. Nitsche, The SARS-CoV-2 main protease as drug target. Bioorg. Med. Chem. Lett. 30, 127377 (2020). doi:10.1016/j.bmcl.2020.127377 Medline

15. C. Ma, M. D. Sacco, B. Hurst, J. A. Townsend, Y. Hu, T. Szeto, X. Zhang, B. Tarbet, M. T. Marty, Y. Chen, J. Wang, Boceprevir, GC-376, and calpain inhibitors II, XII inhibit SARS-CoV-2 viral replication by targeting the viral main protease. Cell Res. 30, 678-692 (2020). doi:10.1038/s41422-020-0356-z Medline

16. Z. Jin, X. Du, Y. Xu, Y. Deng, M. Liu, Y. Zhao, B. Zhang, X. Li, L. Zhang, C. Peng, Y. Duan, J. Yu, L. Wang, K. Yang, F. Liu, R. Jiang, X. Yang, T. You, X. Liu, X. Yang, F. Bai, H. Liu, X. Liu, L. W. Guddat, W. Xu, G. Xiao, C. Qin, Z. Shi, H. Jiang, Z. Rao, H. Yang, Structure of Mpro from SARS-CoV-2 and discovery of its inhibitors. Nature 582, 289-293 (2020). doi:10.1038/s41586-020-2223-y Medline

17. W. Dai, B. Zhang, X. M. Jiang, H. Su, J. Li, Y. Zhao, X. Xie, Z. Jin, J. Peng, F. Liu, C. Li, Y. Li, F. Bai, H. Wang, X. Cheng, X. Cen, S. Hu, X. Yang, J. Wang, X. Liu, G. Xiao, H. Jiang, Z. Rao, L. K. Zhang, Y. Xu, H. Yang, H. Liu, Structure-based design of antiviral drug candidates targeting the SARS-CoV-2 main protease. Science 368 , 1331-1335 (2020). doi:10.1126/science.abb4489 Medline

18. L. Zhang, D. Lin, X. Sun, U. Curth, C. Drosten, L. Sauerhering, S. Becker, K. Rox, R. Hilgenfeld, Crystal structure of SARS-CoV-2 main protease provides a basis for design of improved $\alpha$-ketoamide inhibitors. Science 368, 409-412 (2020). doi:10.1126/science.abb3405 Medline

19. T. Sasaki, M. Kishi, M. Saito, T. Tanaka, N. Higuchi, E. Kominami, N. Katunuma, T. Murachi, Inhibitory effect of di- and tripeptidyl aldehydes on calpains and cathepsins. J. Enzyme Inhib. 3, 195-201 (1990). doi:10.3109/14756369009035837 Medline

20. J. Shang, Y. Wan, C. Luo, G. Ye, Q. Geng, A. Auerbach, F. Li, Cell entry mechanisms of SARS-CoV-2. Proc. Natl. Acad. Sci. U.S.A. 117, 11727-11734 (2020). doi:10.1073/pnas.2003138117 Medline

21. M. Hoffmann, H. Kleine-Weber, S. Schroeder, N. Kruger, T. Herrler, S. Erichsen, T. S. Schiergens, G. Herrler, N. H. Wu, A. Nitsche, M. A. Muller, C. Drosten, S. Pohlmann, SARS-CoV-2 Cell Entry Depends on ACE2 and TMPRSS2 and Is Blocked by a Clinically Proven Protease Inhibitor. Cell 181, 271-280 e278 (2020).

22. T. Liu, S. Luo, P. Libby, G. P. Shi, Cathepsin L-selective inhibitors: A potentially promising treatment for COVID-19 patients. Pharmacol. Ther. 213, 107587 (2020). doi:10.1016/j.pharmthera.2020.107587 Medline

23. D. Dana, S. K. Pathak, A Review of Small Molecule Inhibitors and Functional Probes of Human Cathepsin L. Molecules 25, 698 (2020). doi:10.3390/molecules25030698 Medline

24. Y. Choe, F. Leonetti, D. C. Greenbaum, F. Lecaille, M. Bogyo, D. Brömme, J. A. Ellman, C. S. Craik, Substrate profiling of cysteine proteases using a combinatorial peptide library identifies functionally unique specificities. J. Biol. Chem. 281, 12824-12832 (2006). doi:10.1074/jbc.M513331200 Medline

25. X. Ou, Y. Liu, X. Lei, P. Li, D. Mi, L. Ren, L. Guo, R. Guo, T. Chen, J. Hu, Z. Xiang, Z. $\mathrm{Mu}, \mathrm{X}$. Chen, J. Chen, K. Hu, Q. Jin, J. Wang, Z. Qian, Characterization of spike glycoprotein of SARS-CoV-2 on virus entry and its immune cross-reactivity with SARS-CoV. Nat. Commun. 11, 1620 (2020). doi:10.1038/s41467-020-15562-9 Medline

26. B. Xia, X. Kang, Activation and maturation of SARS-CoV main protease. Protein Cell 2, 282-290 (2011). doi:10.1007/s13238-011-1034-1 Medline
27. G. Ye, X. Wang, X. Tong, Y. Shi, Z. F. Fu, G. Peng, Structural Basis for Inhibiting Porcine Epidemic Diarrhea Virus Replication with the 3C-Like Protease Inhibitor GC376. Viruses 12, 240 (2020). doi:10,3390/v12020240 Medline

28. W. Vuong, M. B. Khan, C. Fischer, E. Arutyunova, T. Lamer, J. Shields, H. A. Saffran, R. T. McKay, M. J. van Belkum, M. A. Joyce, H. S. Young, D. L. Tyrrell, J. C. Vederas, M. J. Lemieux, Feline coronavirus drug inhibits the main protease of SARS-CoV-2 and blocks virus replication. Nat. Commun. 11, 4282 (2020). doi:10.1038/s41467020-18096-2 Medline

29. K. H. Verschueren, K. Pumpor, S. Anemüller, S. Chen, J. R. Mesters, R. Hilgenfeld, A structural view of the inactivation of the SARS coronavirus main proteinase by benzotriazole esters. Chem. Biol. 15, 597-606 (2008). doi:10.1016/i.chembiol.2008.04.011 Medline

30. C. Y. Chou, H. C. Chang, W. C. Hsu, T. Z. Lin, C. H. Lin, G. G. Chang, Quaternary structure of the severe acute respiratory syndrome (SARS) coronavirus main protease. Biochemistry 43, 14958-14970 (2004). doi:10.1021/bi0490237 Medline

31. F. Chow, D. C. Wan, K. B. Wong, Profiling of substrate specificity of SARS-CoV 3CL. PLOS ONE 5, e13197 (2010). doi:10.1371/journal.pone.0013197 Medline

32. T. Muramatsu, C. Takemoto, Y.-T. Kim, H. Wang, W. Nishii, T. Terada, M. Shirouzu, S. Yokoyama, SARS-CoV 3CL protease cleaves its C-terminal autoprocessing site by novel subsite cooperativity. Proc. Natl. Acad. Sci. U.S.A. 113, 12997-13002 (2016). doi:10.1073/pnas.1601327113 Medline

33. S. Yang, S. J. Chen, M. F. Hsu, J. D. Wu, C. T. Tseng, Y. F. Liu, H. C. Chen, C. W. Kuo, C. S. Wu, L. W. Chang, W. C. Chen, S. Y. Liao, T. Y. Chang, H. H. Hung, H. L. Shr, C. Y. Liu, Y. A. Huang, L. Y. Chang, J. C. Hsu, C. J. Peters, A. H. Wang, M. C. Hsu, Synthesis, crystal structure, structure-activity relationships, and antiviral activity of a potent SARS coronavirus 3CL protease inhibitor. J. Med. Chem. 49, 49714980 (2006). doi:10.1021/im0603926 Medline

34. J. J. Shie, J. M. Fang, T. H. Kuo, C. J. Kuo, P. H. Liang, H. J. Huang, Y. T. Wu, J. T. Jan, Y. S. Cheng, C. H. Wong, Inhibition of the severe acute respiratory syndrome $3 \mathrm{CL}$ protease by peptidomimetic alpha,beta-unsaturated esters. Bioorg. Med. Chem. 13, 5240-5252 (2005). doi:10.1016/i,bmc.2005.05.065 Medline

35. L. Zhang, D. Lin, Y. Kusov, Y. Nian, Q. Ma, J. Wang, A. von Brunn, P. Leyssen, K. Lanko, J. Neyts, A. de Wilde, E. J. Snijder, H. Liu, R. Hilgenfeld, $\alpha$-Ketoamides as Broad-Spectrum Inhibitors of Coronavirus and Enterovirus Replication: Structure-Based Design, Synthesis, and Activity Assessment. J. Med. Chem. 63, 4562-4578 (2020). doi:10.1021/acs.jmedchem.9b01828 Medline

36. L. Zhu, S. George, M. F. Schmidt, S. I. Al-Gharabli, J. Rademann, R. Hilgenfeld, Peptide aldehyde inhibitors challenge the substrate specificity of the SARScoronavirus main protease. Antiviral Res. 92, 204-212 (2011). doi:10.1016/i.antiviral.2011.08.001 Medline

37. A. C. Galasiti Kankanamalage, Y. Kim, V. C. Damalanka, A. D. Rathnayake, A. R. Fehr, N. Mehzabeen, K. P. Battaile, S. Lovell, G. H. Lushington, S. Perlman, K. O. Chang, W. C. Groutas, Structure-guided design of potent and permeable inhibitors of MERS coronavirus $3 \mathrm{CL}$ protease that utilize a piperidine moiety as a novel design element. Eur. J. Med. Chem. 150, 334-346 (2018). doi:10.1016/j.ejmech.2018.03.004 Medline

38. M. L. Agostini, E. L. Andres, A. C. Sims, R. L. Graham, T. P. Sheahan, X. Lu, E. C. Smith, J. B. Case, J. Y. Feng, R. Jordan, A. S. Ray, T. Cihlar, D. Siegel, R. L. Mackman, M. O. Clarke, R. S. Baric, M. R. Denison, Coronavirus Susceptibility to the Antiviral Remdesivir (GS-5734) Is Mediated by the Viral Polymerase and the Proofreading Exoribonuclease. mBio 9, e00221-e18 (2018). doi:10.1128/mBio.00221-18 Medline

39. N. C. Pedersen, Y. Kim, H. Liu, A. C. Galasiti Kankanamalage, C. Eckstrand, W. C. Groutas, M. Bannasch, J. M. Meadows, K. O. Chang, Efficacy of a 3C-like protease inhibitor in treating various forms of acquired feline infectious peritonitis. J. Feline Med. Surg. 20, 378-392 (2018). doi:10.1177/1098612X17729626 Medline

40. Y. Kim, H. Liu, A. C. Galasiti Kankanamalage, S. Weerasekara, D. H. Hua, W. C. Groutas, K. O. Chang, N. C. Pedersen, Reversal of the Progression of Fatal Coronavirus Infection in Cats by a Broad-Spectrum Coronavirus Protease Inhibitor. PLOS Pathog. 12, e1005531 (2016). doi:10.1371/journal.ppat.1005531 Medline

41. S. D. Cady, J. Wang, Y. Wu, W. F. DeGrado, M. Hong, Specific binding of adamantane drugs and direction of their polar amines in the pore of the influenza M2 transmembrane domain in lipid bilayers and dodecylphosphocholine micelles 
determined by NMR spectroscopy. J. Am. Chem. Soc. 133, 4274-4284 (2011). doi:10.1021/ja102581n Medline

42. M. T. Marty, A. J. Baldwin, E. G. Marklund, G. K. Hochberg, J. L. Benesch, C. V. Robinson, Bayesian deconvolution of mass and ion mobility spectra: From binary interactions to polydisperse ensembles. Anal. Chem. 87, 4370-4376 (2015). doi:10.1021/acs.analchem. 5 b00140 Medline

43. G. Repetto, A. del Peso, J. L. Zurita, Neutral red uptake assay for the estimation of cell viability/cytotoxicity. Nat. Protoc. 3, 1125-1131 (2008). doi:10.1038/nprot.2008.75 Medline

44. R. Musharrafieh, P. Lagarias, C. Ma, R. Hau, A. Romano, G. Lambrinidis, A. Kolocouris, J. Wang, Investigation of the Drug Resistance Mechanism of M2-S31N Channel Blockers through Biomolecular Simulations and Viral Passage Experiments. ACS Pharmacol. Transl. Sci. 3, 666-675 (2020). doi:10.1021/acsptsci.0c00018 Medline

45. G. A. Kaminski, R. A. Friesner, J. Tirado-Rives, W. L. Jorgensen, Evaluation and reparametrization of the OPLS-AA force field for proteins via comparison with accurate quantum chemical calculations on peptides. J. Phys. Chem. B 105, 6474-6487 (2001). doi:10.1021/ip003919d

46. W. L. Jorgensen, J. Chandrasekhar, J. D. Madura, R. W. Impey, M. L. Klein, Comparison of Simple Potential Functions for Simulating Liquid Water. J. Chem. Phys. 79, 926-935 (1983). doi:10.1063/1.445869

47. W. L. Jorgensen, D. S. Maxwell, J. Tirado-Rives, Development and Testing of the OPLS All-Atom Force Field on Conformational Energetics and Properties of Organic Liquids. J. Am. Chem. Soc. 118, 11225-11236 (1996). doi:10.1021/ja9621760

48. D. Shivakumar, J. Williams, Y. Wu, W. Damm, J. Shelley, W. Sherman, Prediction of Absolute Solvation Free Energies using Molecular Dynamics Free Energy Perturbation and the OPLS Force Field. J. Chem. Theory Comput. 6, 1509-1519 (2010). doi:10.1021/ct900587b Medline

49. T. Darden, D. York, L. Pedersen, Particle Mesh Ewald - an N.Log(N) Method for Ewald Sums in Large Systems. J. Chem. Phys. 98, 10089-10092 (1993). doi:10.1063/1.464397

50. U. Essmann, L. Perera, M. L. Berkowitz, T. Darden, H. Lee, L. G. Pedersen, A smooth particle mesh Ewald method. J. Chem. Phys. 103, 8577-8593 (1995). doi:10.1063/1.470117

51. D. D. Humphreys, R. A. Friesner, B. J. Berne, A Multiple-Time-Step Molecular Dynamics Algorithm for Macromolecules. J. Chem. Phys. 98, 6885-6892 (1994). doi:10.1021/i100078a035

52. J. A. Izaguirre, D. P. Catarello, J. M. Wozniak, R. D. Skeel, Langevin stabilization of molecular dynamics. J. Chem. Phys. 114, 2090-2098 (2001). doi:10.1063/1.1332996

53. S. E. Feller, Y. Zhang, R. W. Pastor, B. R. Brooks, Constant pressure molecular dynamics simulation: The Langevin piston method. J. Chem. Phys. 103, 46134621 (1995). doi:10.1063/1.470648

54. E. F. Pettersen, T. D. Goddard, C. C. Huang, G. S. Couch, D. M. Greenblatt, E. C. Meng, T. E. Ferrin, UCSF Chimera-A visualization system for exploratory research and analysis. J. Comput. Chem. 25, 1605-1612 (2004). doi:10.1002/jcc.20084 Medline

55. W. Minor, M. Cymborowski, Z. Otwinowski, M. Chruszcz, HKL-3000: The integration of data reduction and structure solution-from diffraction images to an initial model in minutes. Acta Crystallogr. D Biol. Crystallogr. 62, 859-866 (2006). doi:10.1107/S0907444906019949 Medline

56. A. Vagin, A. Teplyakov, Molecular replacement with MOLREP. Acta Crystallogr. D Biol. Crystallogr. 66, 22-25 (2010). doi:10.1107/S0907444909042589 Medline

57. G. N. Murshudov, P. Skubák, A. A. Lebedev, N. S. Pannu, R. A. Steiner, R. A. Nicholls, M. D. Winn, F. Long, A. A. Vagin, REFMAC5 for the refinement of macromolecular crystal structures. Acta Crystallogr. D Biol. Crystallogr. 67, 355367 (2011). doi:10.1107/S0907444911001314 Medline

58. P. Emsley, K. Cowtan, Coot: Model-building tools for molecular graphics. Acta

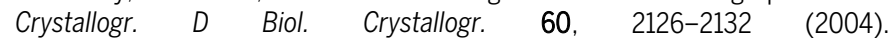
doi:10.1107/S0907444904019158 Medline

59. S. R. Mandadapu, M. R. Gunnam, K. C. Tiew, R. A. Uy, A. M. Prior, K. R. Alliston, D. H. Hua, Y. Kim, K. O. Chang, W. C. Groutas, Inhibition of norovirus 3CL protease by bisulfite adducts of transition state inhibitors. Bioorg. Med. Chem. Lett. 23, 62-65 (2013). doi:10.1016/i.bmcl.2012.11.026 Medline

\section{ACKNOWLEDGMENTS}

Funding: This research was partially supported by the National Institutes of Health (NIH) (Grants Al147325 and Al157046) and the Arizona Biomedical Research Centre Young Investigator grant (ADHS18-198859) to J. W. J. A. T. and M. T. M. were funded by the National Institute of General Medical Sciences and National Institutes of Health (Grant R35 GM128624 to M. T. M.). Y. X. was funded by the National Institutes of Health (NIH) (Grant Al151638). We thank Michael Kemp for assistance with crystallization and $\mathrm{X}$-ray diffraction data collection. We also thank the staff members of the Advanced Photon Source of Argonne National Laboratory, particularly those at the Structural Biology Center (SBC), with X-ray diffraction data collection. SBC-CAT is operated by UChicago Argonne, LLC, for the U.S. Department of Energy, Office of Biological and Environmental Research under contract DE-AC02-06CH11357. The SARS-CoV-2 experiments were supported by a COVID-19 pilot grant from UTHSCSA to Y.X. SARS-Related Coronavirus 2, Isolate USA-WA1/2020 (NR-52281) was deposited by the Centers for Disease Control and Prevention and obtained through BEI Resources, NIAID, $\mathrm{NIH}$. Author Contributions: J. W. and Y. C. conceived and designed the study; C. M. expressed the $\mathrm{M}^{\text {pro }}$ and $\mathrm{PL}$ pro; C.M. performed the $\mathrm{IC}_{50}$ determination, thermal shift-binding assay, and enzymatic kinetic studies; M. S. carried out Mpro crystallization and structure determination with the assistance of X. Z, and analyzed the data with Y. C.; P. L. performed the molecular dynamics simulations under the guidance of A. K.; A. G. and N. K. synthesized the compounds for cocrystallization; Y. H. performed the cytotoxicity assay; X. M. and P. D. performed the SARS-CoV-2 immunofluorescence assay and plaque assay under the guidance of $Y$. X. B. H. and B. T. performed the initial antiviral assay with SARSCoV-2; J A. T. performed the native mass spectrometry experiments with the guidance from M. T. M.; J. W. and Y. C. secured funding and supervised the study; J. W., Y.C., and M.S. wrote the manuscript with the input from others. Competing interests: The authors declare no competing interests. Data Availability: The drug-bound complex structures for SARS-CoV-2 Mpro have been deposited in the Protein Data Bank with accession numbers of 6XA4 (SARS-CoV$2 \mathrm{HM}^{\text {Pro }}+$ Calpain inhibitor II), 6XFN (SARS-CoV-2 HMPro + Calpain inhibitor XII), 6XBG (SARS-CoV-2 HMPro + UAWJ246), 6XBH (SARS-CoV-2 HMPro + UAWJ247), and 6XBI (SARS-CoV-2 HMPro + UAWJ248).

\section{SUPPLEMENTARY MATERIALS}

advances.sciencemag.org/cgi/content/full/sciadv.abe0751/DC1

Submitted 29 July 2020

Accepted 21 October 2020

Published First Release 6 November 2020

10.1126/sciadv.abe0751 

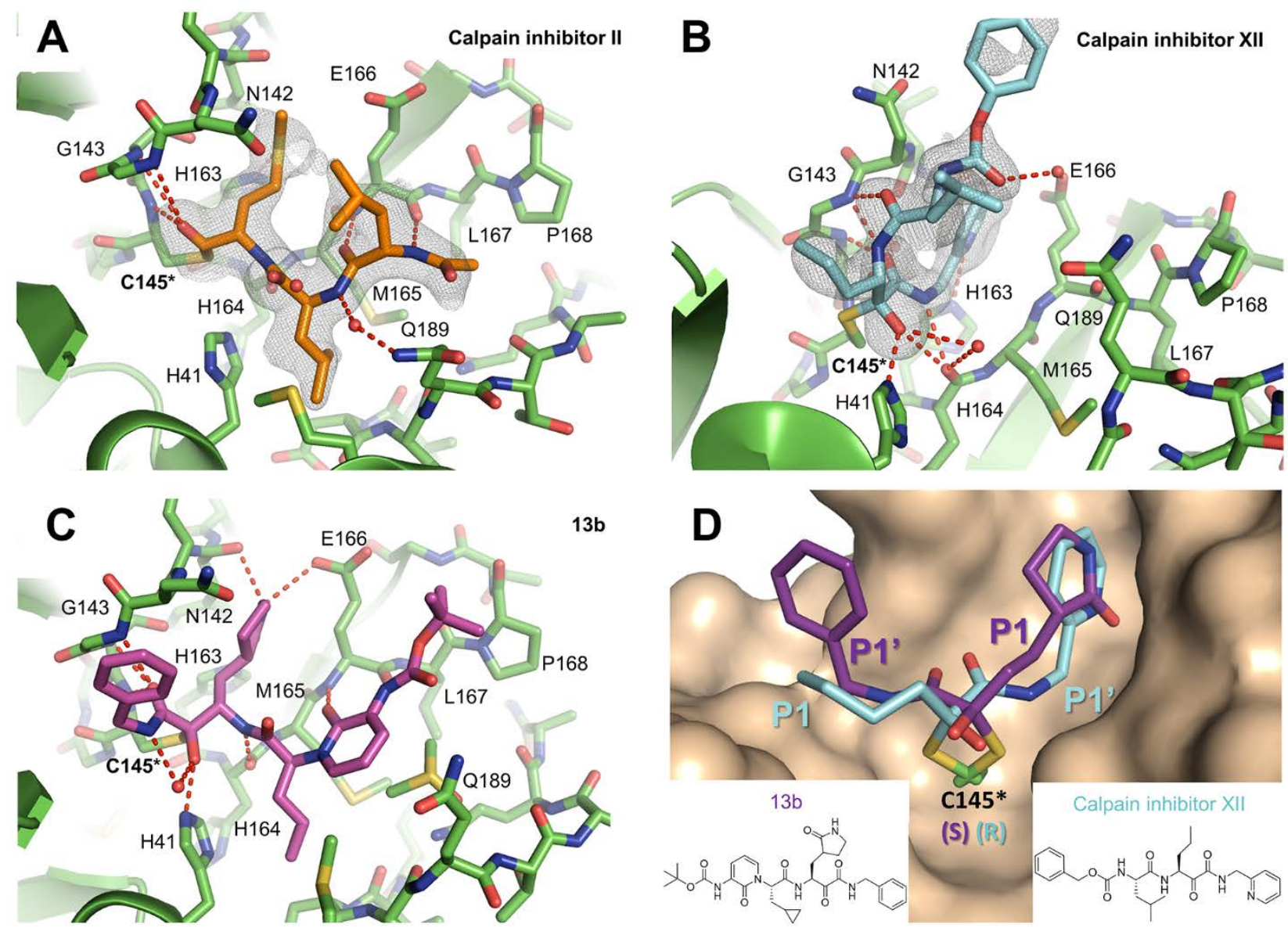

Fig. 1. X-ray crystal structures of SARS-CoV-2 $\mathrm{M}^{\text {pro }}$ in complex with calpain inhibitors II (PDB: 6XA4) and XII (PDB: 6XFN). Unbiased Fo-Fc electron density map, shown in grey, is contoured at $2 \sigma$. Hydrogen bonds are shown as red dashed lines. SARS-CoV-2 $\mathrm{M}^{\text {pro }}$ in complex with (A) calpain inhibitor II (orange) and (B) calpain inhibitor XII (cyan). (C) Binding mode and interactions of a previously reported $\alpha$-ketoamide inhibitor $13 \mathrm{~b}$ (purple, PDB ID 6Y2F) with SARS-CoV-2 $\mathrm{M}^{\text {pro }}$. (D) Close-up comparison of calpain inhibitor XII (blue) and 13b (purple) in the S1 and S1' sites. The P1 pyrrolidinone ring and P1' benzene of 13b occupy the S1 and S1' sites respectively. Conversely, the P1 norvaline and P1' pyridine of calpain inhibitor XII adopt the S1' and S1 sites respectively. Accompanying the non-canonical positioning of the $\mathrm{P} 1$ and $\mathrm{P} 1$ ' moieties, a stereochemical inversion of the thiohemiketal adduct with Cys145 is observed for calpain inhibitor XII. Like all other known $\alpha$ ketoamide inhibitors, $13 \mathrm{~b}$ adopts a (S) configuration. However, calpain inhibitor XII forms a covalent adduct in the (R) configuration. 
A

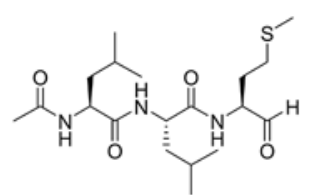

Calpain inhibitor II

B

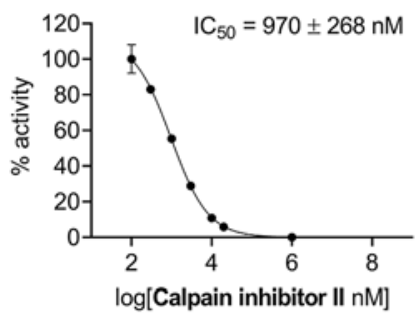

F

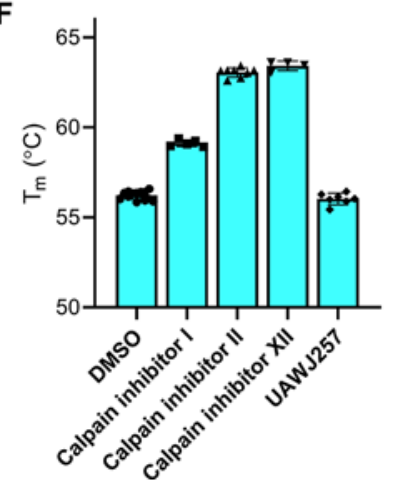

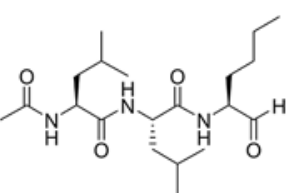

Calpain inhibitor I

C

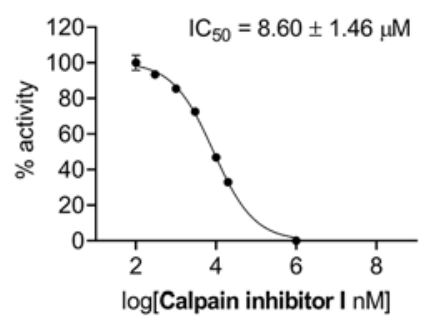

G

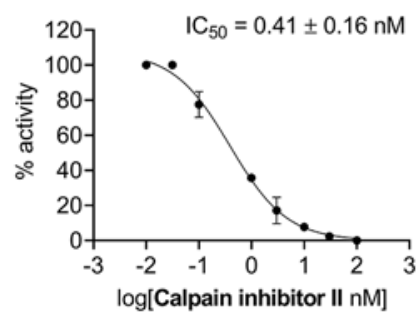

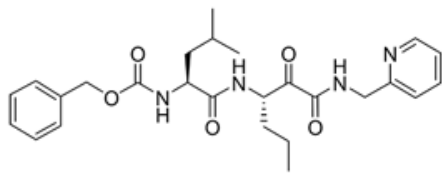

Calpain inhibitor XII

D

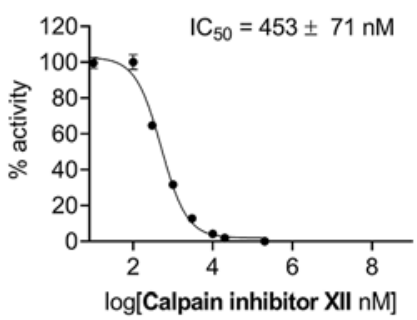

H

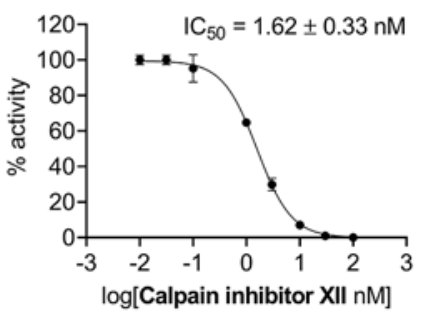

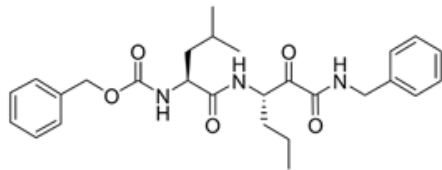

UAWJ257

E

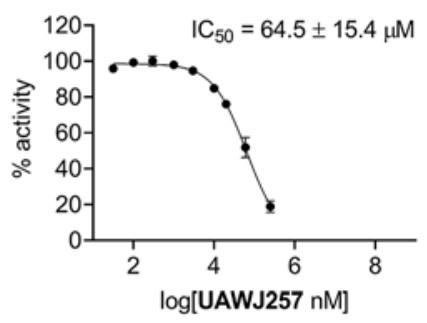

I

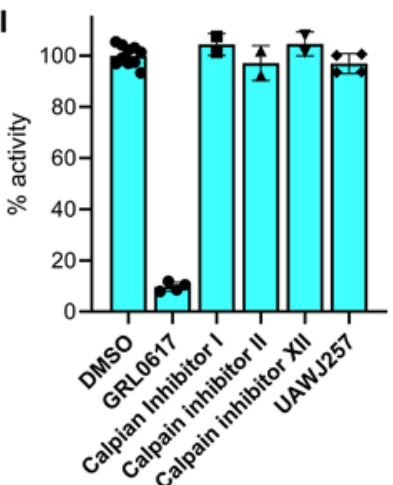

Fig. 2. Biochemical and biophysical characterizations of calpain inhibitors II and XII and their analogs as SARS-CoV-2 Mro inhibitors. (A) Chemical structures of calpain inhibitors II, I, XII, and UAWJ257. (B-E) $\mathrm{IC}_{50}$ plots from in vitro FRET-based enzymatic assay against SARS-CoV-2 $\mathrm{M}^{\text {pro }}$ of calpain inhibitor II (B); calpain inhibitor I (C); calpain inhibitor XII (D); and UAWJ257 (E). (F) Thermal shift binding assay of calpain inhibitors and their analogs with $3 \mu \mathrm{M}$ SARS-CoV-2 Mpro protein. $40 \mu \mathrm{M}$ compounds were pre-incubated with $\mathrm{M}^{\text {pro }}$ protein for $30 \mathrm{~min}$ at $30^{\circ} \mathrm{C}$. $\mathrm{T}_{\mathrm{m}}$ was calculated as described in method section. $(\mathrm{G}-\mathrm{H}) \mathrm{IC}_{50}$ plots from in vitro FRET-based enzymatic assay against human cathepsin $L$ of calpain inhibitor II (G) and calpain inhibitor XII (H). (I) Counter screening of calpain inhibitors II, I, and XII, and UAWJ257 against SARS-CoV-2 PL pro in the FRET-based enzymatic assay. GRL0617 was added as a positive control. The calculated enzymatic activity with each compound was normalized to DMSO control. The results are average \pm standard deviation of two or more repeats. 
A

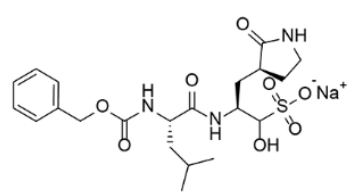

GC-376

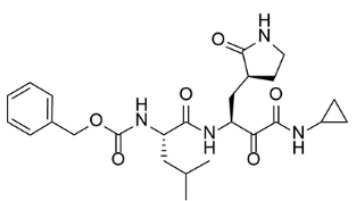

UAWJ246

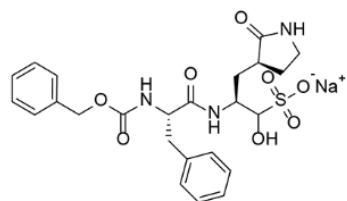

UAWJ247

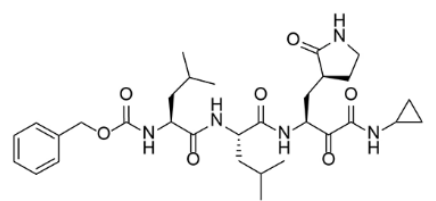

UAWJ248
B

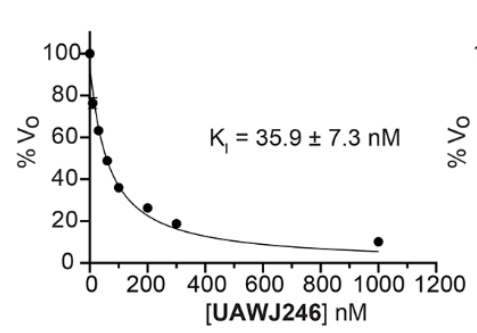

F
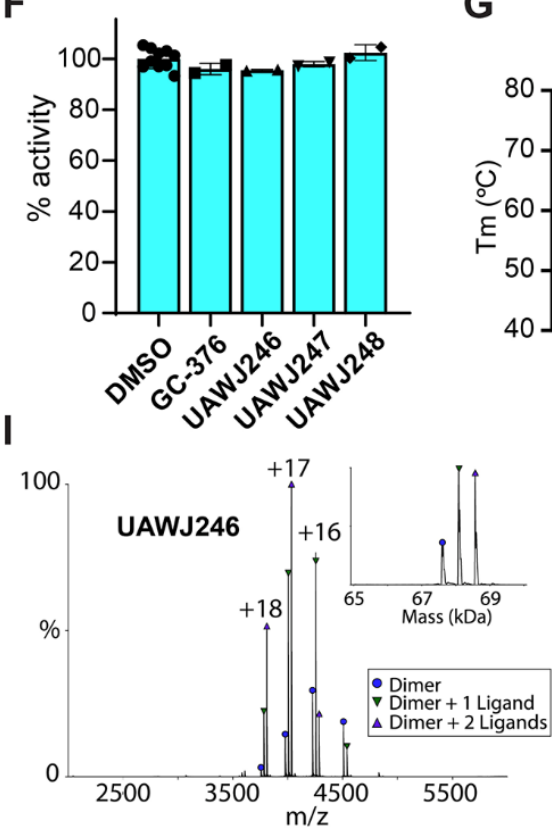

C

G
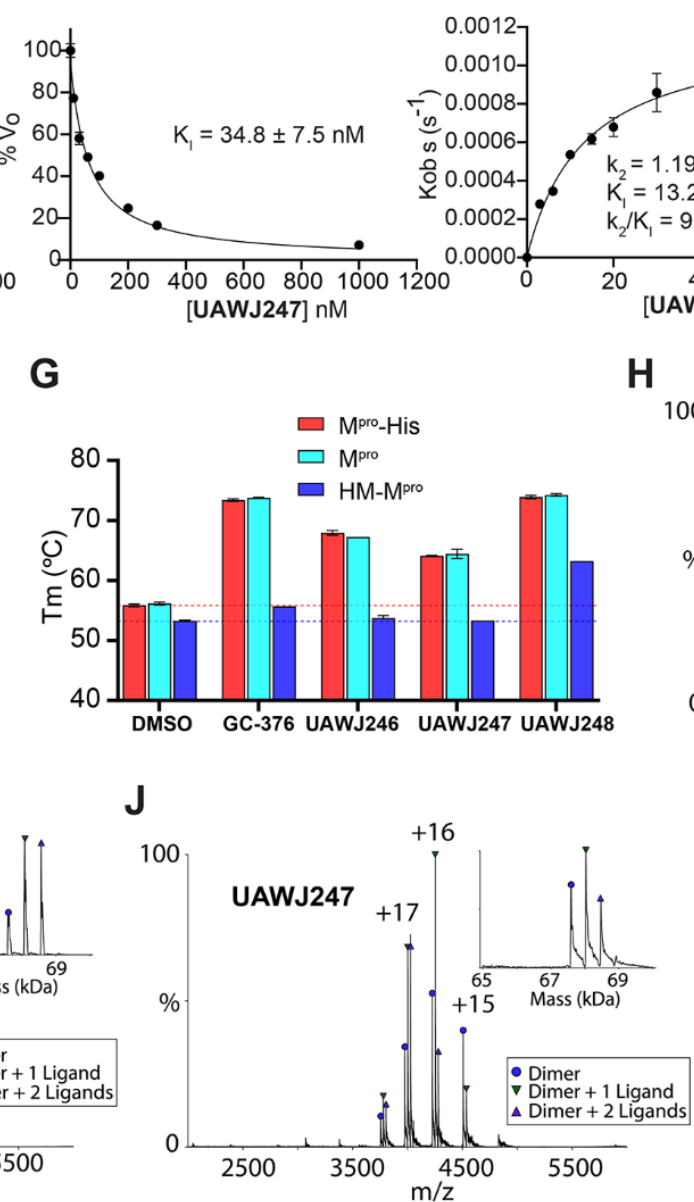

H
E

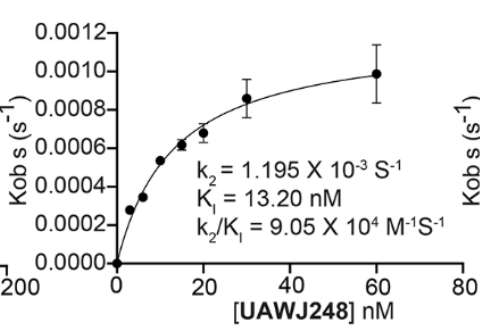

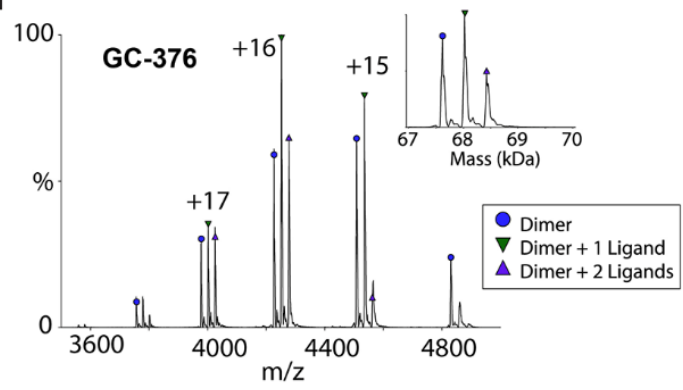

K

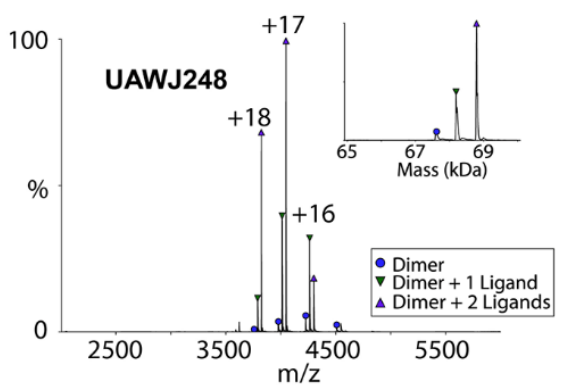

Fig. 3. Pharmacological characterization of the mechanism of action of GC-376 analogs UAWJ246, UAWJ247, and UAWJ248 in inhibiting SARS-CoV-2 Mpro. (A) Chemical structures of GC-376, UAWJ246, UAWJ247, and UAWJ248. (B-E) Morrison plot of the proteolytic reaction progression curves of SARS-CoV-2 $\mathrm{M}^{\text {pro }}$ in the presence or the absence of compounds. Original proteolytic reaction progression curves were in fig. S4. Detailed methods were described in "Materials and methods" section. UAWJ246 (B); UAWJ247 (C); UAWJ248 (D), and GC-376 (E). (F) Counter screening of GC-376, UAWJ246, UAWJ247, and UAWJ248 against SARS-CoV-2 PL pro in the FRET-based enzymatic assay. (G) Thermal shift binding assay of GC-376 analogs with different SARS-CoV-2 $\mathrm{M}^{\text {pro }}$ constructs. ( $\mathrm{H}-\mathrm{K}$ ) Binding of inhibitors to SARS-CoV-2 $\mathrm{M}^{\text {pro }}$ using native mass spectrometry. Native mass spectra with the inset deconvolved spectra revealing ligand binding to with $(\mathrm{H}) 10$ $\mu \mathrm{M}$ GC-376 added, (I) $10 \mu \mathrm{M}$ UAWJ246, (J) $10 \mu \mathrm{M}$ UAWJ247 added, and (K) $10 \mu \mathrm{M}$ UAWJ248 with 4 mM DTT added. The peaks are annotated with the blue circle as the dimer, green down triangle as the dimer with one ligand bound, and the purple up triangle as the dimer with two ligands bound. 

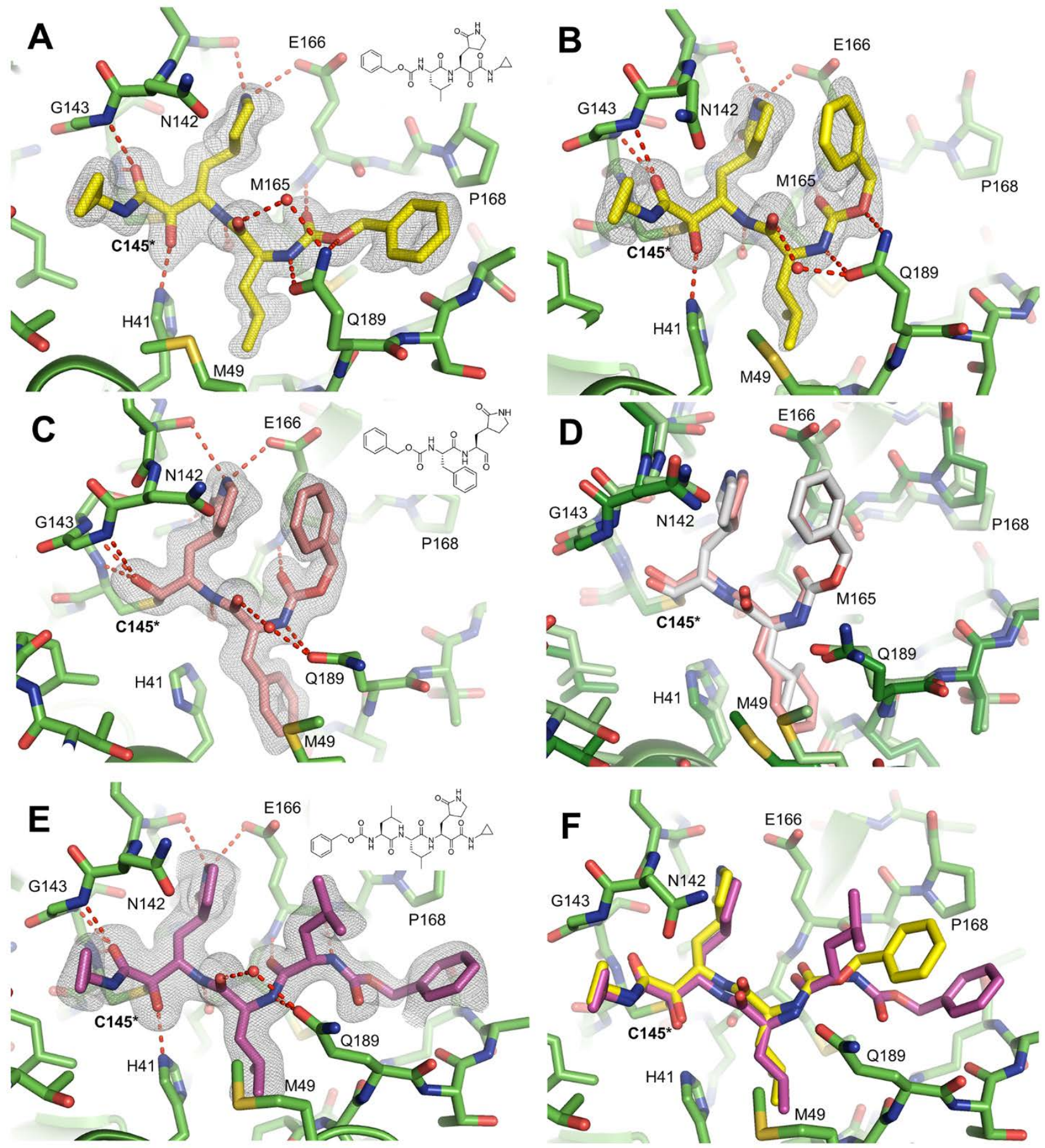

Fig. 4. SARS-CoV-2 $\mathrm{M}^{\text {pro }}$ in complex with GC-376 analogs. Unbiased Fo-Fc electron density map, shown in grey, is contoured at $2 \sigma$. Hydrogen bonds are shown as red dashed lines. Solved as a dimer in the $P 2_{1}$ spacegroup, two different conformations of the Cbz group of UAWJ246 were observed in the (A) protomer $A$ and (B) protomer B. (C) The complex structure of UAWJ247, revealing the P2 position can accommodate a Phe side chain. (D) Comparison of the binding poses of UAWJ247 (dark green/salmon) and GC-376 (light green/grey, PDB ID 7BRR). (E) The complex structure of UAWJ248, solved as a dimer in the P1 space-group. Protomer $A$ is shown here, and the inhibitor binding pose is identical in protomer B (fig. S8). (F) Comparison of the binding poses of of UAWJ248 (purple) and UAWJ246 (yellow) in protomer A. 
A

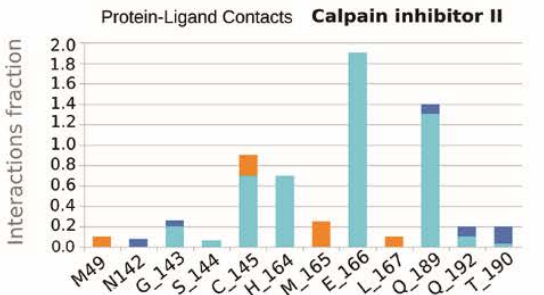

Hydrogen Bond $\quad$ Hydrophobic interaction Water Bridge

C

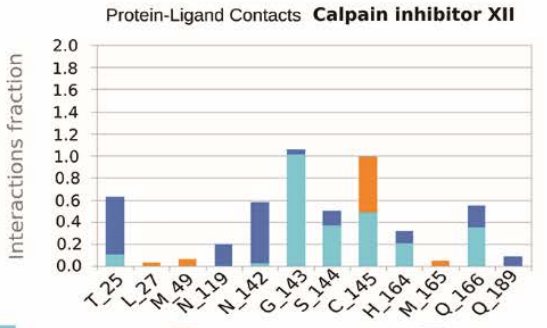

Hydrogen Bond - Hydrophobic interaction Water Bridge

E

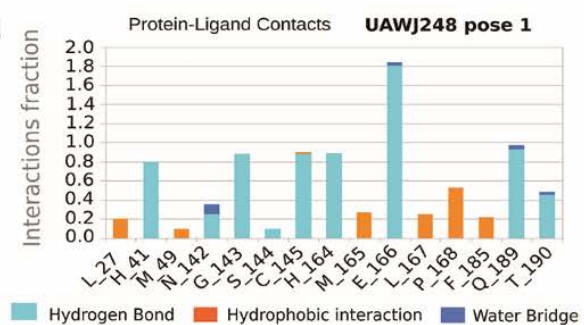

G
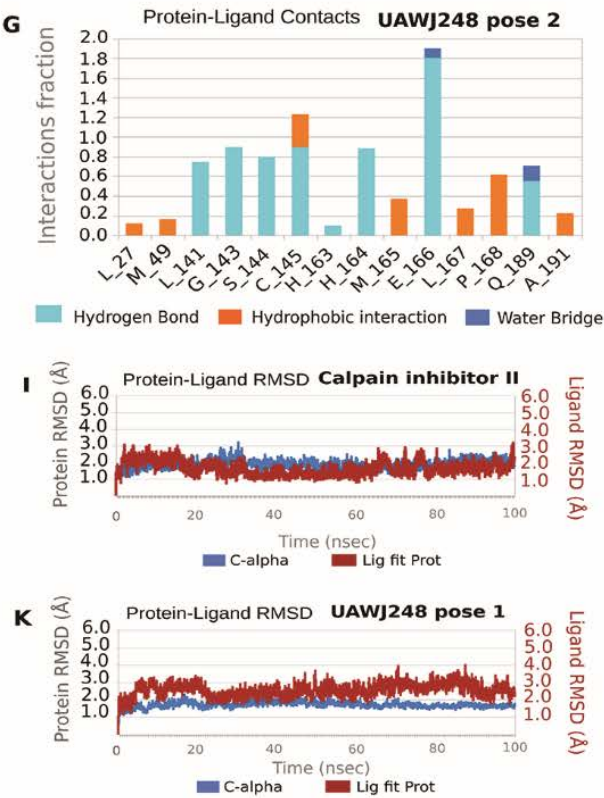

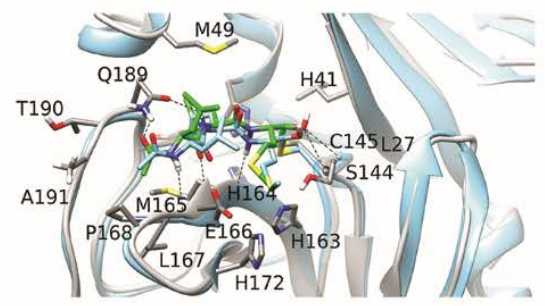

D

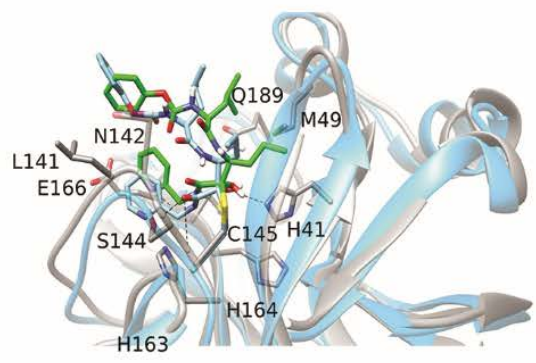

$\mathbf{F}$

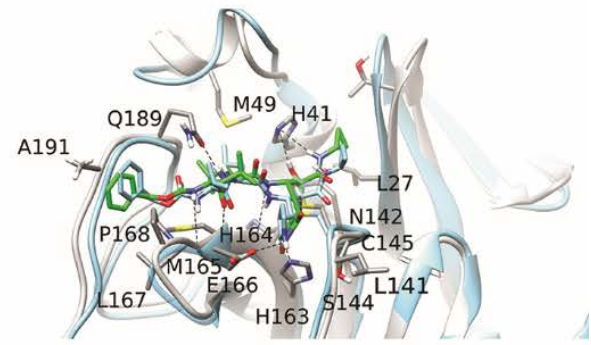

H

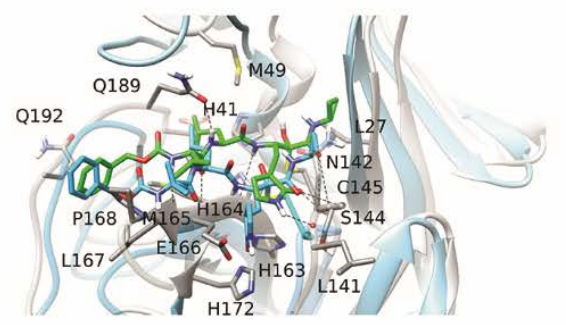

J

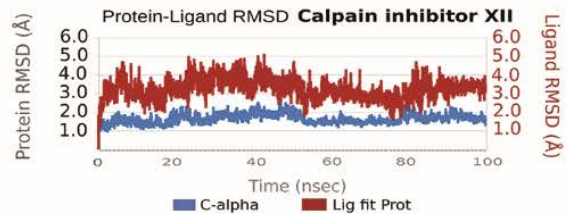

L

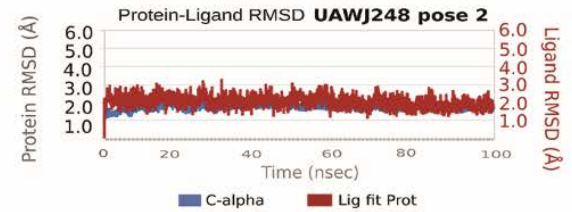

Fig. 5. MD simulations of SARS-CoV-2 $\mathrm{M}^{\text {pro }}$ with calpain inhibitors II and XII, and UAWJ248. In (A), (C), (E), (G) hydrogen bonding interactions bar is depicted in light blue, van der Waals in orange, water bridges in blue. Interactions are plotted from 100-ns MD simulations for the complexes of the covalently bound calpain inhibitor II, calpain inhibitor XII, UAWJ248 (pose 1: first protomer), UAWJ248 (pose 2: second protomer) in the active site of SARS-CoV-2 $\mathrm{M}^{\text {pro. }}$. They are considered important when frequency bar is $\geq 0.2$. In (B), (D), (F), (H) the last snapshots of the above mentioned 100ns-MD simulated complexes overlaid with experimental structures with PDB IDs 6XA4, 6XFN, 6XBI, respectively, are shown. In (I), (J), (K), (L) the RMSD plots of $\mathrm{C} \alpha$ carbons (blue diagram, left axis) and of ligand (red diagram, right axis) of the above mentioned 100ns-MD simulated complexes are shown. 


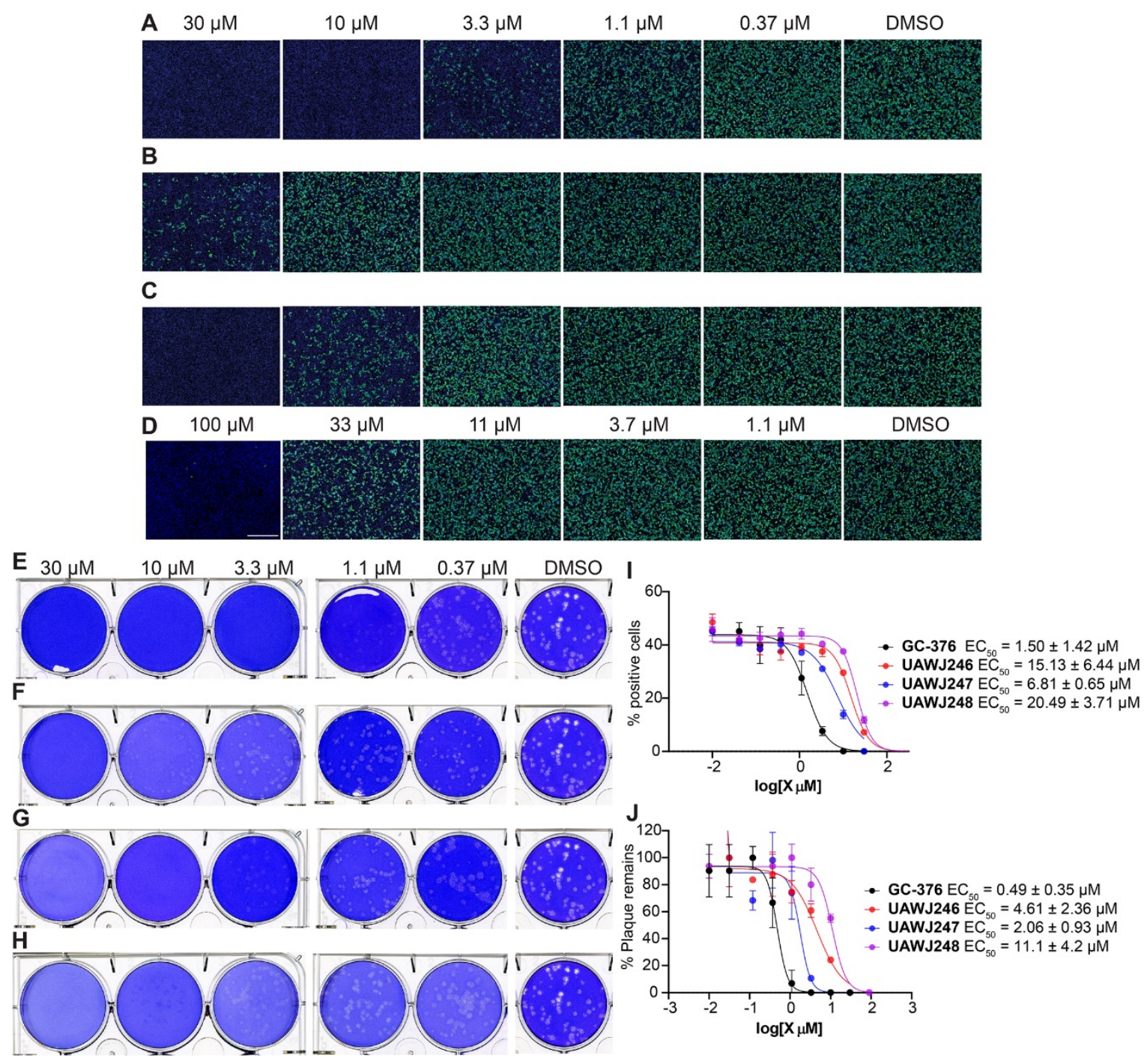

Fig. 6. Antiviral activity of GC-376 analogs. A-D Antiviral activity of GC-376 analogs against SARS-CoV-2 in the immunofluorescence assay. (A) GC-376; (B) UAWJ246; (C) UAWJ247; (D) UAWJ248. Vero E6 cells in a 96-well plate were infected with SARS-CoV-2 (USA-WA1/2020 isolate) at $\mathrm{MOI}$ of 0.05 in the presence of the indicated concentrations of the tested compounds. At $48 \mathrm{hpi}$, the cells were fixed and stained with a rabbit monoclonal antibody against the SARSCoV-2 NP and a secondary antibody conjugated with Alexa 488 (Green). The nuclei were counterstained with Hoechst dye (Blue). For each well, fluorescence images of approximately $10 \mathrm{~K}$ cells were acquired and shown. The images are representatives of three repeats. E-H Antiviral activity of GC-376 analogs against SARS-CoV-2 in the plaque assay. (E) GC-376; (F) UAWJ246; (G) UAWJ247; (H) UAWJ248. Vero E6 cells in 6-well plates were infected with approximately 40 PFU/well of SARS-CoV-2 (USA-WA1/2020 isolate). After 1 hour, the inoculum was removed, and the cells were overlaid with medium containing the indicated concentrations of the tested compounds and 1.2\% Avicel RC-591. At 3 dpi, the overlay was removed, and the cells were stained with $0.2 \%$ crystal violet. The images are representatives of two repeats. Data fitting of the antiviral activity of GC-376 analogs against SARS-CoV-2 in the immunofluorescence assay $(\mathrm{I})$ and the plaque assay $(\mathrm{J})$. 